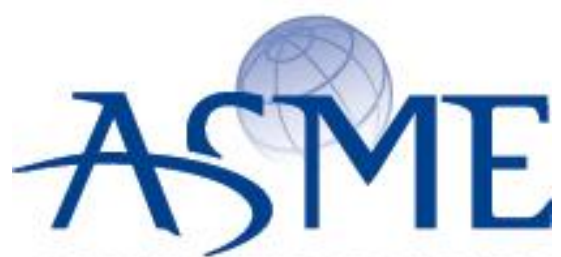

SETTING THE STANDARD

\section{American Society of Mechanical Engineers}

ASME Accepted Manuscript Repository

Institutional Repository Cover Sheet

University of Hull

ASME Paper Title: Experimental investigation of the vertical upward single and two-phase flow pressure drops

through gate and ball valves

Authors: $\quad$ Ammar Zeghloul, Hiba Bouyahiaoui , Abdelwahid Azzi , Abbas H. Hasan, Abdelsalam Al-sarkhi

ASME Journal Title: Journal of fluids engineering

Volume/Issue $142 / 2$

Date of Publication (VOR* Online) 04/10/2019

ASME Digital Collection URL: $\underline{\text { https://doi.org/10.1115/1.4044833 }}$

DOI:

$10.1115 / 1.4044833$

CASME

Distribution: Creative Commons Licence: Attribution 4.0 International License. See:

http://creativecommons.org/licenses/by/4.0/

*VOR (version of record) 


\title{
Experimental investigation of the vertical upward single and two-phase flow pressure drops through gate and ball valves
}

\author{
Ammar Zeghloul \\ University of Sciences and Technology Houari Boumedien \\ BP 32 El Alia, Bab Ezzouar, Alger 16111, Algeria \\ Polytechnic National School \\ B.P. 182, El Harrach, Algiers, 16200, Algeria \\ E-mail : a-zeghloul@live.fr
}

Hiba Bouyahiaoui

University of Sciences and Technology Houari Boumedien

BP 32 El Alia, Bab Ezzouar, Alger 16111, Algeria

\begin{abstract}
Abdelwahid Azzi
University of Sciences and Technology Houari Boumedien

BP 32 El Alia, Bab Ezzouar, Alger 16111, Algeria
\end{abstract}

\author{
Abbas H. Hasan \\ University of Hull-Chemical Engineering, Hull, United Kingdom
}

\begin{abstract}
Abdelsalam Al-sarkhi
Department of Mechanical Engineering, King Fahd University of Petroleum \& Minerals, Saudi Arabia
\end{abstract}

\begin{abstract}
:
This paper presents an experimental investigation of the pressure drop through valves in vertical upward flows. Experiments were carried out using a 11/4" (DN 32) ball and gate valve. Five opening areas have been investigated from fully open to the nearly fully closed valve, using air with a superficial velocity of $(0-3.5 \mathrm{~m} / \mathrm{s})$ and water $(0.05-0.91 \mathrm{~m} / \mathrm{s})$. These ranges cover single-phase and the bubbly, slug and churn two-phase flow regimes. It was found that for the single-phase flow experiments, the valve coefficient increases with the valve opening and is the same, in both valves, for the openings smaller than $40 \%$. The single-phase pressure drop increases with the liquid flowrate and decreases with the opening area. The two-phase flow pressure drop was found considerably increased by reducing the opening area for both valves. It reaches its maximum values
\end{abstract}


at $20 \%$ opening for the ball valve and $19 \%$ opening for the gate valve. It was also inferred that at fully opening condition, the two-phase flow multiplier, for both valves, has been found close to unity for most of the tested flow conditions. For the 40 and $20 \%$ valve openings the two-phase multiplier decreases in the power-law with liquid holdup for the studied flow conditions. Models proposed originally for evaluating the pressure drop through an orifice in single-phase and twophase flows were also applied and assessed in the present experimental data.

Key Words: Two-phase flow, gate valve, ball valve, pressure drop, vertical, upward. 


\section{Introduction}

Valves are vital components in many pipeline systems applied in different industries such as petroleum, hydraulic and pneumatic industries. They are mainly used for controlling and regulating the fluid flow. The latter is achieved by varying the resistance of the valve applied to the system by modulating its closing position. Among the valves, the gate and ball valves are widely used due to their simplicity and performance. Additionally, they are easy to be manipulated when motorized.

In single-phase flow, numerous studies have been conducted to understand the flow characteristic through valves and more largely to the pressure drop associated with these geometries. Morris [1] provided more interesting information of liquid flow through a safety valve in which he presented two-parameter model expressed in two terms, the discharge coefficient, $\mathrm{C}_{\mathrm{d}}$ of the valve nozzle and the loss coefficient, $\mathrm{K}$ of the valve body. Recently, Kim and No [2] investigated experimentally the critical pressure and critical flow rate in a safety valve at different water subcooling temperatures ranging from 10 to $125 \mathrm{~K}$. Their results show that the critical flow rate through the valve is principally dependent on the inlet flow conditions; while the geometrical characteristics of the safety valve show a relatively small effect on it.

Other studies focused on the geometrical parameters that can affect the pressure drop across the valve. These parameters can be attributed to two basic causes. The first is the variation in trim design, generally not linear in nature. The second one is valve throttling. As the valve closes the opening area of the valve throat is reduced.

In order to study the structure and behaviour of the shaded vortices around the V-Port ball valve, Merati et al. [3] carried out experimental and computational works. Pressure gauges were utilized to measure the pressure drop associated with the valve. Additionally, a Kistler quartz dynamic pressure sensor was installed downstream of the test section to record the pressure fluctuations in 
the fluid and determine the Strouhal frequency. Downstream of the valve, the mean velocity, and turbulence intensity were measured by the intermediary of a Laser Doppler Velocimetry (LDV). The structure of the flow around the valve was visualized by a high-speed video camera (NAC1000) at 500 frames per second. On the other hand, a two-dimensional fluid dynamics model of the valve and the associated pipes was developed using Fluent software. The results showed the existence of a dominant large three-dimensional vortex downstream of the valve and the Strouhal number was found to be independent of the valve opening. Similarly, the control of the flow rate in a ball valve using V-Port has been analyzed by Chern et al. [4]. Three-dimensional numerical simulation and experimental investigation were achieved to analyze the flow patterns and to measure the performance coefficients. The test was performed from 50 to $100 \%$ opening valves and three V-Ports angles $\left(30^{\circ}, 60^{\circ}\right.$, and $\left.90^{\circ}\right)$. The 3D Numerical simulation was achieved using the finite volume method employed by STAR-CD commercial CFD package. Additionally, experiments were carried out in a closed-loop water piping system with a diameter of $38 \mathrm{~mm}$. An inclined mercury U-tube manometer was utilized to evaluate the pressure drop across the ball valve. The pressure tapping points of the inclined manometer are $2 \mathrm{D}$ upstream and $6 \mathrm{D}$ downstream of the valve according to ANSI/ISA [5]. Moreover, the particle tracking flow visualization method was applied to observe the flow patterns. The study showed that $30^{\circ}$ and $60^{\circ} \mathrm{V}$-Ports could linearly control the volume flow rate from 50 to $100 \%$ opening. This was not the case for the $90^{\circ}$, which did not exhibit such linearity.

Lately, the cavitation phenomena were the goal of the study presented by Chern et al. [6]. They used a different opening of a ball valve for the water flow conditions. The inlet velocity was visualized by the intermediary of a particle tracking flow visualization technique and the pressure drop across the valve was measured with an inclined mercury U-tube manometer. They observed that the cavitation phenomena can occur only under certain flow conditions. 
Cui et al. [7] investigated experimentally and numerically the opening and closing dynamic characteristics of a ball valve. They measured the flow rate, inlet and outlet pressures as a function of the time during the opening and closing of the valve. The results obtained from experiments were used then as boundary conditions in numerical simulation using the commercial CFD software "Ansys-Fluent". The results showed the existence of three vortices with two in the valve channel and one downstream which may affect the flow in the valve.

Choke valve type was investigated by Lin et al. [8], who performed a numerical and experimental study of the sleeve-regulating valve. The experimental facility including a horizontal pipe of a 0.05 $\mathrm{m}$ diameter and two pressure sensors were positioned at 5D upstream and 10D downstream the valve respectively. Their results showed that the adding of the regulator was responsible for decreasing the value of flow coefficient $\left(\mathrm{K}_{\mathrm{V}}\right)$ and that the decrease was greater with large valve opening.

A three-dimensional computational fluid dynamics simulation through a ball valve using STARCD software have established by Moujaes and Jagan [9]. Three valve opening position have been chosen, $(100,66$, and $33 \%$ opening). Their study focused on the loss coefficient, $\mathrm{k}$, and the flow coefficient, $\mathrm{Cv}$. The simulation results were compared with the data of Chen et al. [4] and the American Society of Heating, Refrigerating, and Air conditioning Engineers (ASHRAE) data on valves. They indicated that the $\mathrm{k}$ factor is independent of the Reynolds number. Additionally, the coefficient, $\mathrm{Cv}$ values strongly increase with the valve opening and weakly influenced by the Reynolds number.

Wang and Bai [10] proposed a model of the ball valve to studying the resistance loss and pressure drop based on the experimental results obtained by Cui et al. [7], Shi et al. [11] and Chern et al. 
[6]. In their model, they divided the geometrical mechanism of the ball valve into three equivalent throttling (a thick orifice, two variable-opening eccentric orifice plates, and a $\mathrm{Z}$ type elbow).

In two-phase flow, less effort has been devoted for measurement of pressure drop through valves compared to that in single-phase flow. Tremblay and Andrews [12] investigated the hydraulic characteristics of steam-water flow across the globe valve. Measurements were made in $1 / 2$ inch horizontal channel including needle-type globe valve with a mass quality up to $64 \%$. The pressure drop was measured by differential pressure cells. Five different models were utilized to correlate the pressure drop data. They reported that the homogeneous model was the best one even at qualities up to $64 \%$. Sookprasong et al. [13] obtained pressure drop data from experimental tests performed in $76.2 \mathrm{~m}$ long horizontal flow loop made of steel with $5.08 \mathrm{~cm}$ pipe diameter including components such as gate and globe valves. For these components, there were eight pressure taps, one upstream and seven downstream. The single-phase pressure drop provided by each component was used to calculate the pressure resistance coefficient. For an individual component, a pressure recovery length between 10 and 50 pipe diameters was suggested, depending on the flow rate. The resistance coefficient for two-component separated by a distance less than the recovered length was found to be greater than the summation of each individual resistance coefficient. Hwang and Pal [14] studied experimentally the loss coefficients for fully-open and half-open globe and gate valves. Experiments were conducted in a horizontal stainless-steel test facility with an inner diameter of $2.72 \mathrm{~cm}$. Six pressure transducers installed upstream and downstream the valve were used to measure the pressure drop. The emulsion (oil-in-water or water-in-oil related to the concentration $64 \mathrm{Vol} \%$ ) was monitored by an in-line conductance cell. They found that the loss coefficients are not considerably influenced by the emulsion concentration. Van Lookeren Campagne et al. [15] analyzed the two-phase bubbly flow in a ball valve with a pressure calculation method using the CFD package AVL-Fire. They noticed that the geometry of the valve might yield 
to the bubble deformation, and more obvious for large bubbles. Alimonti et al. [16] carried out experiments by using multiple orifice valves with three throat thickness diameter ratios. Two pressure taps were employed to measure the pressure drop placed at 1D from the connection flanges. The gas fraction of the two-phase mixture was calculated from the pressure drop over $1 \mathrm{~m}$ length below the upstream choke flange which was measured by a differential pressure gauge. He noticed a significant effect of the multiple orifice valves geometry on the hydrodynamic characteristics of the flow. The calculated two-phase flow multiplier was compared with the models proposed in the literature. No one of the model tested was found capable to predict well the experimental results. A new relationship was proposed for the two-phase flow gas-liquid pressure drop multiplier for multiple orifice valves. Alimonti [17] performed an experimental characterization study of single and two-phase flow through a globe and a gate valves 2" DN. Different opening areas are examined. He determined the flow coefficient of the valve for the single-phase flow. The predictive models have been compared with two-phase flow measured data. He found that the Chisholm model gives a good approach with the two-phase multiplier for the globe valve, and the modified model predicted by Lockart-Martinelli gives the best agreement for the gate valve. In both models, the average error is less than $\pm 10 \%$.

It can be concluded from the literature review presented previously that compared to other fittings and throttling devices, such as orifices, Venturis, T-junctions, etc., a few research in literature have been carried out to demonstrate the pressure drop of two-phase flows through valves. Moreover, very limited research has been performed on gate and ball valves, particularly in two phase flows, despite the importance and the large applications of those types of valves. To fill this gap, a detailed experimental investigation of single and two-phase pressure drop flow through $1 \frac{1 / 4}{4}$ gate and ball valve positioned in a vertical pipe is carried out in the present work. The influence of the valves geometry and their openings, as well as the two-phase mixture configurations, on the pressure drop, are investigated. Furthermore, an assessment of the correlations proposed for predicting the single 
and two-phase flow pressure drop was achieved. Moreover, the relationship between the pressure drop and the flow pattern transitions at different valve opening percentage for both Ball and Gate valves are discussed. A thorough understanding of such relationship is essential for safe and efficient design of valves and other related equipment.

\section{Theoretical background}

The correct selection of the valve with an adequate size is important for the proper functioning of the hydraulic installations. Under-sizing of the selected valve will yield to a significant loss of pressure in the valve that may reduce the desired flow rate and causing vaporization of liquid at the outlet of the valve. On the other hand, an over-sizing of the valve will result in an irregular flow control due to an insufficient pressure drop and in turns, might increase the cost of installations.

One of the more important parameters used in the selection procedure of any valve is the valve coefficient $\mathrm{K}_{\mathrm{v}}$, which presents the experimental volumetric flow in $\mathrm{m}^{3} / \mathrm{h}$ or $1 / \mathrm{min}$ achieved through a valve, per unit of the pressure loss (bar). It is expressed in the following equation

$$
\mathrm{K}_{\mathrm{v}}=\mathrm{Q} \sqrt{\frac{\gamma}{\Delta \mathrm{P}}}
$$

where $\mathrm{Q}$ is the volume flow rate in $\left(\mathrm{m}^{3} / \mathrm{h}\right.$ or in $\left.1 / \mathrm{min}\right), \gamma$ is the relative density with respect to water (liquids) and $\Delta \mathrm{P}$ is the pressure drop in (bar) measured across the valve,

Another expression equivalent to equation (1) can be found in the literature which combined the flow area, $A$, of the valve orifice, the discharge coefficient $\mathrm{C}_{\mathrm{d}}$, and the flow area coefficient $\mathrm{C}_{\mathrm{a}}$, as given by equation (2),

$$
\mathrm{K}_{\mathrm{v}}=\mathrm{AC}_{\mathrm{d}} \mathrm{C}_{\mathrm{a}} \sqrt{\frac{2}{\rho_{\mathrm{w}}}}
$$

where $\rho_{\mathrm{w}}$ is water density. 
The pressure drop of the single-phase flow across the valve (which is mainly due to the flow restriction) and the changing of the flow direction are both directly proportional to the velocity of the flow, U. The two parameters related by a coefficient called the flow resistance coefficient K, which characterized the pressure drop through the valve, i.e.:

$$
\Delta \mathrm{P}_{\mathrm{SP}}=\mathrm{K} \rho \mathrm{U}^{2} / 2
$$

Another approach used in the prediction of the single-phase flow pressure drop across valves is that used for an orifice because of the high geometric similarity between the two singularities. According to Chisholm [18], orifices having t/D (Thickness to diameter ratio) greater than 0.5 can be categorized as thin orifices while those with t/D less than 0.5 are classified as thick orifices. The pressure drop of a single-phase flow across a thin orifice is expressed as:

$$
\Delta \mathrm{P}_{\mathrm{SP}}=\frac{\rho \mathrm{U}^{2}}{2}\left(\frac{1}{\sigma \sigma_{v c}}-1\right)^{2}
$$

where $\sigma=\left(\frac{\mathrm{d}_{\text {orifice }}}{D_{\text {pipe }}}\right)^{2}$ is the orifice open area, $\sigma_{v c}=\left(\frac{\mathrm{d}_{v c}}{D_{\text {pipe }}}\right)^{2}$ the vena contracta area with respect to the pipe area, $U$ the mean velocity in the pipe.

A pressure drop in a single phase flow across the thick orifices is quite different than thin ones because of the double expansion of the flow. The expression of the pressure drop for thick orifice is given as:

$$
\Delta \mathrm{P}_{\mathrm{SP}}=\frac{\rho \mathrm{U}^{2}}{2}\left[\left(\frac{1}{\sigma \sigma_{v c}}\right)^{2}-1-\frac{2}{\sigma^{2}}\left(\frac{1}{\sigma_{v c}}-1\right)-2\left(\frac{1}{\sigma_{v c}}-1\right)\right]
$$

To estimate and quantify the pressure drop under two-phase flow conditions, a multiplier is introduced to the pressure drop obtained from a single-phase flow analysis. This dimensionless multiplier is called "two-phase flow pressure drop multiplier", $\Phi_{\mathrm{LO}}^{2}$, and can be written as: 


$$
\Phi_{\mathrm{LO}}^{2}=\Delta \mathrm{P}_{\mathrm{TP}} / \Delta \mathrm{P}_{\mathrm{LO}}
$$

Table 1 summarizes the most cited models used for predicting the pressure drop across valves and orifices as reported by Alimonti [17] and Zeghloul el al. [19]. All these models are expressed as a function of $\Phi_{\mathrm{LO}}^{2}$.

Table 1: Two-phase flow correlations of pressure drop multiplier in orifices and valves [19].

Table 1 indicates that all these correlations are expressed in term of masse flow quality, $x$, and both phases gas and liquid densities, $\rho_{\mathrm{g}}$ and $\rho_{\mathrm{l}}$, respectively. It is worth noting that other parameters such as surface tension, gravity and viscosity are not taken into account in these correlations. Moreover, only Chisholm's correlation (B-equation) has taken into consideration the effect of the geometry on the two-phase multiplier. Thus, it is necessary to test the applicability of these correlations/equations for two-phase flow conditions.

\section{Experimental setup and procedure}

The experiments presented in this work were performed in the facility located at the Laboratory of Multiphase Flows and Porous Media of the University of Sciences and Technology Houari Boumedien, Algiers. A schematic diagram of this facility is shown in Fig.1.

To visualize the flow pattern, the test-section was made of transparent acrylic resin (PMMA) with a total length of about $6 \mathrm{~m}$. Tap water is pumped, from a tank, into the mixer using a centrifugal pump. The storage tank serves as a separator to separate the gas and liquid phases in the facility. The water flow rate was controlled using three different calibrated rotameters mounted in parallel 
with a maximum uncertainty of $2 \%$. The air supplied by the compressor was adjusted with three different calibrated rotameters with a maximum uncertainty of $2 \%$. Airflow static pressure was measured before entering the mixer. A thermocouple (calibrated in the range of $0-100{ }^{\circ} \mathrm{C}$ ) was used to measure the temperature with an accuracy of $\pm 1 \%$. The water is combined with the air at the mixing section. For more details on the mixer used in the present work, see Zeghloul et al. [20]. The conditions of the gas and liquid superficial velocity are Ugs $=0$ to $3.5 \mathrm{~m} / \mathrm{s}$ and Uls $=0.05$ to $0.92 \mathrm{~m} / \mathrm{s}$ respectively. A valve is mounted $4.3 \mathrm{~m}$ after the phase mixer, which presents a sufficient distance for the flow to be developed.

To measure the void fraction, a conductance probe was installed $16 \mathrm{D}$ upstream of the valve. It consists of a pair of ring electrode made of stainless-steel with direct contact of the fluid flow. Several researchers used with success the conductance probe technique to measure the void fraction among them Fossa [21], Saidj et al. [22]. For further details on this technique see Zeghloul et al. [23].

To ensure maximum accuracy, two FOXBORO differential pressure transmitters are selected to measure the pressure difference across the valve. The pressure ranges of these two transmitters are 0 to $7.2 \mathrm{kPa}$ and 0 to $36 \mathrm{kPa}$, respectively with $2 \%$ full-scale accuracy. The location of the pressure tappings is selected according to ISO 5167 [24]. In other words, they are connected to the DP cell at $1 \mathrm{D}$ (upstream) and $1 / 2 \mathrm{D}$ (downstream) of the orifice. In this case, the valve restriction is very similar to an orifice and the recommendation of ISO 5167 has been followed.

In the other hand, three identical absolute pressure transmitters IMPRESS Sensors were used to cover the values of the high-pressure drop. The range and accuracy of this absolute pressure transmitters are $(0-160 \mathrm{kPa})$ and $0.1 \%$, full scale. One absolute pressure transmitter was installed 2D below (upstream) of the valve and the other two are located 6D and 16D respectively downstream of the valve. 


\section{Fig.1. A Schematic diagram of the experimental test facility}

Fig. 2 shows the two commercial valves ((a) gate valve, (b) ball valve) with $1 \frac{1 / 4}{4}$ size used in this study. The opening of these two singularities was examined by five different opening sections from a fully open section with opening decreasing by a step of $20 \%$ each time.

\section{Fig. 2. Gate and ball valve used in the experiments}

To ensure the correct measurement of the two-phase pressure drop is implemented, a constant density must be kept in the pressure measurement lines, i.e. it must be ensured that there are no air bubbles. For this purpose, a purge system shown in Fig. 3 was employed.

Before starting the measurements, the drain valves are opened; the water coming from the pump through the transparent plastic tubes will push the air bubbles in the direction of the pressure tapping and in the other side to the differential pressure transmitter. Once it is seen that there are no more air bubbles in the pressure tappings lines, all the purging systems valves are closed and measurements are carried out.

\section{Fig. 3. Purging system arrangement used in the pressure drop (DP) measurements}

The data gathered from the conductance probe, absolute pressure transmitters, and the DP cells were all acquired (with the help of LabVIEW) by a NI-DAQ, 12 bit-6092E unit. $200 \mathrm{~Hz}$ (as a sampling time for the captured data) were used in which each flow condition run for $60 \mathrm{~s}$ (therefore, 12000 data point for each run). 


\section{Experimental results and discussion}

\subsection{Evaluation of the valve characteristics}

Fig. 4 displays the valve coefficient $K_{v}$, as a function of the valve opening of the $1 \frac{1 / 4}{\text { " gate and ball }}$ valves. The opening is varied from 20 to $100 \%$. The standard deviation of the experimentally measured values of the valve coefficient is also plotted in this graph. $K_{v}$ was calculated from (1).

\section{Fig. 4. Valve characteristic curves; Valve coefficient vs. opening percentage}

It is seen from this figure that the variation of the valve coefficient (for both ball and gate valves) with the valve opening represents an 'equal percentage' characteristics where the relationship between them are exponential. It is also clear that for the valve opening below $40 \%, \mathrm{Kv}$ for both valves are almost similar while the difference becomes significant as the valve opening increases beyond $40 \%$. Above $40 \%$, ball valve indicates higher $\mathrm{K}_{\mathrm{v}}$ values than the gate valve. This deviation in two valve characteristic curves is principally due to the difference in valve geometries. The high value of the $\mathrm{K}_{\mathrm{v}}$ will result in high flowrate through the ball valve.

The measured flow resistance coefficient $\mathrm{K}$, expressed in a dimensionless number as a function of the opening of the gate valve have been used to check the accuracy of the prediction models of Alimonti [17], Miller [30] and Idel'chik [31]. The results are plotted in Fig. 5.

This parameter is often used to express the pressure drop in a single-phase flow. It is seen from this figure that the flow resistance coefficient, $\mathrm{K}$ increased with decreasing valve opening. This is due to the flow being blocked by the valve ball and gate wall and require further energy to move through. The higher value of the $\mathrm{K}$ coefficient obtained from experimental data is 18 , at $20 \%$ 
opening. In addition, the experimental data obtained by Alimonti [17] for a gate valve of 2" DN as well as the literature data given by Miller [25] are very close to the present experimental measurements of the flow resistance coefficient. The values obtained from the correlation given by Idel'chik [26] are in good agreement to the experimental results for an opening greater than $60 \%$. For an opening area less than $60 \%$, the correlation given by Idel'chik deviates significantly from the experimental results and other presented models, particularly at $20 \%$ valve opening area. The experimental data presented in this section can be used as a source of validation (or testing the accuracy) for a number of existing models and correlations already available in literature such as; Alimonti [17], Miller [30] and Idel'chik [31].

\section{Fig. 5. Flow resistance coefficient vs. opening of the $1 \frac{1 / 4}{4}$ DN gate valve}

The evolution of the flow resistance coefficient as function of the opening of the ball valve is plotted in Fig. 6 . Once more, the present data have been used to test the accuracy of the literature data of the ball valve reported by Miller [25] and the values obtained by using the relationship of Idel'chik [26]. One can notice that similarly to the gate valve, the data reported by Miller [25] are very close to the experimental results. For the data reported by Idel'chik [26] only the values for an opening greater than $80 \%$ are in good agreement with the experimental data. Outside this range, the data reported by Idel'chik overpredict the experimental results especially for a $20 \%$ opening where the resistance coefficient can reach 100 times the experimental values.

One can conclude that for the study, the literature data reported by Miller [25] exhibited a high accuracy in predicting of the flow resistance coefficient and therefore the single-phase pressure drop in the gate and ball valves.

Fig. 6. Flow resistance coefficient vs. opening of the $1 \frac{1 / 4}{4}$ DN ball valve 


\subsection{Single-phase flow pressure drop through the valve}

The evolution of the pressure drop through the gate valve with the water flow rate is plotted in Fig. 7 . Five opening areas have been tested from $20 \%$ to $100 \%$. From this figure, it can be seen that for all openings, the pressure drop increases with the water flow rate. The reduction of the opening section causes an increase in the pressure drop. This is due to the fact that the fluid needs more energy to pass through the restriction causing a large pressure difference between upstream and downstream of the valve. The maximum pressure drop has been found for the $20 \%$ openings. For this opening area, the fitting exerts a high resistance on the fluid flow which reaches a maximum value that cannot be exceeded which is known as the critical flowrate. In our experimental measurements, a maximum flowrate of $40 \mathrm{~L} / \mathrm{min}$ for a $20 \%$ opening of the gate valve has been found.

\section{Fig. 7. Single-phase pressure drop of the gate valve}

Fig. 8 shows the pressure drop through the ball valve as a function of the water flow rate. Six opening areas have been tested from fully open to the nearly closed valve. From this figure, one can remark that the behavior of the pressure drop through a ball valve is similar to that of the gate valve. Lower values of pressure drop have been found in the ball valve by considering the same open area as the gate valve $(100,80$, and $60 \%)$. In the other hand, the $19 \%$ opening area of the ball valve shows higher values of the single-phase pressure drop compared to the gate valve with the closest opening, 20\%. This is due to the design and construction of the valves, which has a great impact on the single-phase flow pressure drop. 
Fig. 8. Single-phase pressure drop of the ball valve.

\subsection{Two-phase flow pressure drop through the valve}

\subsubsection{Gate valve}

The variation of the vertically upward two-phase flow pressure drop through the gate valve as a function of the gas superficial velocity for different valve opening values is shown in Fig. 9 . The two-phase pressure drop trends are represented by the mean values of the pressure drop measurement and the error bars show the uncertainties in the pressure drop measurements. The dashed lines indicate the transition between each two flow regimes (i.e.. bubbly to slug and to churn). The identification of these flow patterns transition has been achieved by following the same procedures adopted previously by Zeghloul et al. [23, 19]. From these graphs, one can remark that the curves present the same tendency for all openings. They display three different slops depending on the two-phase flow regime. Pressure drop, $\Delta \mathrm{P}_{\mathrm{TP}}$ is significantly influenced by the valve opening area in which $\Delta \mathrm{P}_{\mathrm{TP}}$ considerably increases by reducing the opening area.

It can be noticed that at a fixed liquid superficial velocity, Uls, the pressure drop, $\Delta \mathrm{P}_{\mathrm{TP}}$ increases with the increasing the gas superficial velocity, Ugs. Similarly, at a given gas superficial velocity, $\Delta \mathrm{P}_{\mathrm{TP}}$ increases with increasing Uls.

Fig. 9-e, corresponding to an opening area of $20 \%$ exhibits the highest values of the pressure drop. In this figure, the maximum value of $\triangle \mathrm{PTP}$ (i.e. $\sim 120 \mathrm{kPa}$ ) was reached at the corresponding Uls and Ugs of $0.8 \mathrm{~m} / \mathrm{s}$ and $2.4 \mathrm{~m} / \mathrm{s}$ respectively, which represents two-phase flow critical conditions for this opening. Otherwise, under these conditions of gas and liquid superficial velocities, the twophase pressure in the upstream of the valve only allows for a constant amount of liquid and gas to pass through this constriction. This principle of flow regulation is typically used in the choke valve. 
Fig. 9. Variation of the pressure drop, $\Delta$ PTP with Ugs at different values of Uls and different opening areas of the gate valve.

\subsubsection{Ball valve}

A thorough understanding of the relationship between the pressure drop and the flow regime transitions at different valve opening in two phase flows is very important for the equipment design in terms of safety, economy, performance and efficiency. Such relationship needs further investigation, both experimentally as well as theoretically.

Fig. 10 illustrates the variation of the two-phase flow pressure drop with the Ugs for different values of Uls at different opening areas of the ball valve. The general trends in these graphs are quite similar to those seen in the gate valve. The pressure drop, $\Delta \mathrm{P}_{\text {TP }}$ depends on the flow regimes which in turn depends on the gas \& liquid superficial velocities. By comparing the pressure drop, $\Delta \mathrm{P}_{\mathrm{TP}}$ of two valves for identical openings $(100,80$, and $60 \%)$, it appears clearly that the ball valve indicates the lower magnitude of the two-phase flow pressure drop for all conditions of gas and liquid superficial velocities. In contrast, 19\% opening area of the ball valve (Fig.10-f) shows higher values of two-phase pressure drop compared to the gate valve with the closest opening area, $20 \%$ (Fig.10-e). In addition, the two-phase flow critical conditions for $19 \%$ ball valve opening indicated by the top most condition reached of gas and liquid superficial velocities, $0.7 \mathrm{~m} / \mathrm{s}$ and $1.67 \mathrm{~m} / \mathrm{s}$ respectively are lower than those found by the gate valve. This may be due to the spherical shape of the ball valve which is more complete at an opening of $19 \%$ and which opposes the movement of the two-phase flow. In other words, the pressure in the upstream of the ball valve that leads to the maximum flow isreached with relatively low gas and liquid velocities conditions compared to those of the gate valve. 
A thorough understanding of the relationship between the pressure drop and the flow regime transitions at different valve opening in two phase flows is very important for the equipment design in terms of safety, economy, performance and efficiency. Such relationship needs further investigation, both experimentally as well as theoretically.

Fig. 10. Variation of the pressure drop, $\Delta \mathbf{P}_{\mathrm{TP}}$ with $\mathrm{U}_{\mathrm{gs}}$ at different values of Uls and different opening areas of the ball valve

\subsection{Pressure drop multiplier of two-phase}

In Fig. 11, the experimental two-phase pressure drop multiplier of the valves was compared with some existent models. For fully opening area (Fig. 11-a), the experimental data of the ball valve (denoted as B.V. experiments in the legend) shows that the two-phase pressure drop multiplier, $\Phi_{\mathrm{LO}}^{2}$ is close to 1 and it seems to be independent on the mass flow quality, $x$ for a wide range of $x$ (i.e. up to $x=0.005$ ). $\Phi_{\mathrm{LO}}^{2}=1$ means that the pressure drop for both single-phase and two-phase flow are identical. For $x>0.005$, it appears that $\Phi_{\mathrm{LO}}^{2}$ becomes less than 1 . It is also seen that at $100 \%$ opening, the experimental data of both ball and gate valves at low values of $x$ (i.e. $x<0.001$ ) are close to each other which are also in good agreement with other models, as shown in Fig. 11-a. in addition, at moderate mass flow quality, $x$ (i.e. from 0.001 to 0.006 ), most of the $\Phi_{\mathrm{LO}}^{2}$ data for the gate valve lies above 1 .

Moreover, comparison of the experimental two-phase flow multiplier for both valves with predicted models summarized in Table 1 shows that Chisholm [18], Simpson et al. [27], Morris [28] and homogeneous models are overpredicting the present experimental data. The other correlations predict well the experimental points for mass flow qualities less than 0.001 . Therefore, doubt may occur regarding the reliability of these correlations for predicting the two-phase flow pressure drop in the full opening valve condition. 
For the $80 \%$ opening area (Fig. 11-b), the experimental data for both valves present two sets. The first group shows a plateau with two-phase flow multiplier around 1.0, which indicates that under $80 \%$ opening area and a given gas \& liquid superficial velocity, the valves geometry has a weak effect on the two-phase flow pressure drop. The second group takes place very close to the models of Chisholm [18], Simpson et al. [27] and Morris [28], while the other correlations are reliable at $\mathrm{x}<0.001$, except the homogeneous- model which fits well for low values of $\mathrm{x}$, i.e. where $\mathrm{x}<0.0005$, indicating that the homogeneous model matches well with low values of gas superficial velocity (i.e. at bubbly flow). Zeghloul et al [19, 20], reported similar findings of the two-phase flow pressure drop multiplier across the orifice.

For the $60 \%$ opening area (Fig. 11-c), a large part of experimental data for gate and ball valves present a good agreement with the models of Chisholm [18], Simpson et al. [27] and Morris [28]. Again, the models of Watson et al. [29], Collins and Gacesa [30] and James [31] showed a good agreement with the data from experiments below a mass flow quality $x<0.001$. In addition, at lower values of $x$ (i.e. $x<0.0005$ ), the homogenous model can predict well the experimental data for both ball and gate valves.

In Fig. 11-d, the experimental data for the $40 \%$ gate valve opening and $35 \%$ ball valve opening fits in a large area. Practically, the experimental data points lie between the Morris and Collins and Gacesa correlations while the homogeneous model overpredicts the two-phase flow multiplier for mass flow quality greater than 0.0005 . Moreover, it must be pointed out that the experimental data for both valves are more concentrated around the models of Chisholm [18], Simpson et al. [27] and Morris [28].

For $20 \%$ valve opening area (Fig. 11-e), the experimental data are located between the two models of Simpson et al. [27] and Watson et al. [29]. The experimental data points of $19 \%$ ball valve opening area are slightly below those of the gate valve with an opening of $20 \%$. The models of Watson et al. [29], James [31] and Collins and Gacesa [30] show the closest curves to the 
experimental data of the ball valve while the models of Chisholm [18] and Morris [28] overpredict the experimental data of both valves for mass flow quality up to 0.001 . Identically to the other openings, the homogeneous model has a good agreement with both valves experimental data at lower values of $x$ (i.e. $x<0.0005)$.

Fig. 11. Comparison between experimental and predicted two-phase flow pressure drop multiplier for different gate valve and ball valve openings.

Fig.12 shows measured two-phase pressure drop multiplier for both valves versus the average liquid holdup measured upstream of the valves at different valves openings. It appears that the trends are not similar for all cases and changing with the liquid holdup for different valves openings toward self-similar behaviour at small openings. For the $100 \%$ opening, the majority of the values of the multiplier are close to unity for both valves; with an exception for the gate valve for which scatter values greater than unity are observed for some cases. By decreasing the opening to $80 \%$ (Fig.12-b), two discernible trends are noticed for both valves and merging to unity as the liquid holdup increases. For the gate valve and for a liquid superficial velocity greater than $0.4 \mathrm{~m} / \mathrm{s}$, the multiplier decreases with the liquid holdup in the form of a power law and is close to unity for the rest of the superficial velocities. Similarly, the multiplier evolves in the power law manner with liquid holdup for a liquid superficial velocity greater than $0.58 \mathrm{~m} / \mathrm{s}$ and is practically equal to unity for the other investigated liquid superficial velocities. For lower openings, 40 and $20 \%$ the twophase multiplier decrease in the power-law form with the liquid holdup for the whole investigated ranges of the liquid and gas superficial velocities.

Fig. 12. Valve two-phase flow pressure drop multiplier versus the upstream liquid holdup, blue symbol (gate valve), red symbol (ball valve). 
To assess the accuracy of the models used in the prediction of the $\Phi_{\text {LO }}^{2}$ (i.e. two-phase flow multiplier) of the valves, plots of experimental data and theoretical two-phase flow multiplier are shown in Fig.13. The approach given by Govan [32] was used to determine the accuracy of the mentioned models. Govan [32] reported several ways of calculating the distribution of deviations (errors) between experimental data \& prediction models for large data sets, e(i). He deduced that the logarithmic distribution ratio of the experimental and predicted values tends to give a Gaussian distribution, while the other methods are generally not. To describe the overall performance of each model, Govan proposed to utilize two error distribution parameters, $F \& S$. where $F$ is the correction factor (i.e. an average factor that should be multiplied by the calculated value to yield the experimental value. $S$ is simply the transformed-standard-deviation which is equal to $\exp (\sigma)-1$, where $\Phi_{\mathrm{LO} \text {, mod }}^{2}(\mathrm{i})$ is the predicted two-phase flow pressure drop multiplier and $\Phi_{\mathrm{LO} \text {, exp }}^{2}(\mathrm{i})$ is the pressure drop multiplier of two-phase flow. Therefore, the following equations can be used;

$$
\begin{aligned}
& F=\frac{1}{\exp (\mathrm{M})} \\
& \mathrm{S}=\exp (\mathrm{R})-1 \\
&\text { with: } \left.\mathrm{M}=\frac{1}{\mathrm{n}} \sum_{\mathrm{i}=1}^{\mathrm{n}} \mathrm{e}(\mathrm{i}) \quad \mathrm{i}\right)=\log \left[\frac{\Phi_{\mathrm{LO}, \bmod }^{2}(\mathrm{i})}{\Phi_{\mathrm{LO}, \exp }^{2}(\mathrm{i})}\right] \\
& \mathrm{R}=\sqrt{\frac{1}{\mathrm{n}} \sum_{\mathrm{i}=1}^{\mathrm{n}}(\mathrm{e}(\mathrm{i})-\mathrm{M})^{2}}
\end{aligned}
$$

Fig. 13, shows that the homogeneous model seems to overpredict the two-phase flow multiplier for a wide range of $x$ regardless of the valve opening area.

For the $80 \%$ opening area, the correlation of Chisholm [18] and Collins and Gacesa [30] are the closest models to the experimental data for gate and ball valve respectively. Looking at the results, 
a question may be raised about the reliability of these models, knowing that an accuracy of $50 \%$ has been found.

For both openings, 60 and $40 \%$ of the gate valve, the models of Simpson et al. [27] and Chisholm [18] predict well the experimental data. This can also be confirmed in Table 2, where the F and S values are close to unity \& zero, respectively. For the openings, 60 and $40 \%$ of the ball valve, the models of Morris [28] and Chisholm [18] show the best prediction as the data points lie on a diagonal line. It should be noted that with these two openings the majority of the points lies within a tolerance range of $35 \%$.

For the smallest tested openings, 20 and $19 \%$ for gate and ball valves respectively, the two best prediction models for gate valve are those of Simpson et al. [27] and Watson et al. [29], while the models of Watson et al. [29] and Collins and Gacesa [30] are the optimum correlations which are predicting the ball valve experimental data. These findings are also verified by Table 2 . in addition, the majority of the points located inside the two dashed lines which presenting a tolerance range of $35 \%$.

Fig. 13. Comparison between predicted \& experimental two-phase flow multiplier

Table 2: Comparison of the experimental two-phase flow multiplier data and the selection of correlations

\section{Conclusion}

Single and two-phase flow pressure drop through gate and ball valves have been investigated experimentally. The valve coefficient $\mathrm{K}_{\mathrm{v}}$ showed identical values for an opening of less than $40 \%$, 
whilst for an opening beyond $40 \%$, the ball valve presented greater values. On the other hand, the experimental results of the flow resistance coefficient show a good agreement with the results presented by Miller [25] as well as the experimental results reported by Alimonti [17] for the gate valve. Additionally, the single-phase pressure drop through gate and ball valves is greatly influenced by the opening. It increases with decreasing of the opening. In addition, the pressure drops values of the gate valve are higher than those of ball valve for the openings of $(60,80$ and $100 \%$ ). However, the opposite is observed for $19 \%$ opening of the ball valve and the smallest opening of $20 \%$ of the gate valve.

In two-phase flow the pressure drops through the valves is discernible by three distinct regions, each characterized by its own slope corresponding to bubbly, slug and churn flow regimes. The opening area of the valves affects significantly the two-phase pressure drop as well as the gas and liquid superficial velocities.

For low openings, 40 and $20 \%$ the two-phase multiplier decreases in the power-law with liquid holdup for the whole investigated flow conditions.

Comparison of experimental two-phase flow multiplier for both valves with predicted models proposed in the literature shows that for a full opening area (100\%), the two-phase multiplier models overpredict the experimental data for a very large domain of mass flow quality. Nevertheless, the majority of experimental points lies with a two-phase multiplier around 1. For $80 \%$ opening area, the most accurate models for gate valve are those of Morris [28] and Chisholm [18], while those of James [31] and Collins and Gacesa [30] predict fairly well the experimental data of the ball valve. In both valves, an average error of $\pm 50 \%$ has been found for the two-phase multiplier prediction models. For $60 \%$ and $40 \%$ opening area, the most favorable model to predict the two-phase multiplier experimental data of both valves is that of Chisholm [18] with an average 
error of $\pm 35 \%$. For $20 \%$ opening area and for both valves the model of Watson et al. [22] is the most reliable one with an error of $\pm 35 \%$. 


\section{Appendix A}

Fig. 14. Ball valve orifice area, (a) ball valve longitudinal-section, (b) $x-y$ projection plane of the ball valve orifice area [10].

Fig. 15. Details of the ball valve orifice area in $x-y$ projection plane [10].

According to Wang and Bai [10], there are $\mathrm{S}_{\mathrm{ACB}}$

$$
\begin{gathered}
\mathrm{S}_{\mathrm{ADB}}=\mathrm{S}_{\mathrm{AO}_{2} \mathrm{~B}}-\frac{1}{2} \mathrm{AB} \times \mathrm{O}_{2} \mathrm{E} \\
\mathrm{S}_{\mathrm{ACB}}=\mathrm{S}_{\mathrm{AO}_{1} \mathrm{~B}}-\frac{1}{2} \mathrm{AB} \times \mathrm{O}_{1} \mathrm{E} \\
\mathrm{S}_{\mathrm{AO}_{1} \mathrm{~B}}=\frac{\angle \mathrm{AO}_{1} \mathrm{~B}}{2 \pi} \mathrm{S}_{\mathrm{O}_{1}} \\
\mathrm{~S}_{\mathrm{AO}_{2} \mathrm{~B}}=\frac{\angle \mathrm{AO}_{2} \mathrm{~B}}{2 \pi} \mathrm{S}_{\mathrm{O}_{2}} \\
\mathrm{~S}_{\mathrm{O}_{1}}=\pi \mathrm{r}^{2} \\
\mathrm{~S}_{\mathrm{O}_{2}}=\pi \mathrm{r}^{2} \cos \theta
\end{gathered}
$$

The equation of a circle $\mathrm{O}_{1}$ :

$$
x^{2}+y^{2}=\mathrm{r}^{2}
$$

The equation of a circle $\mathrm{O}_{2}$ :

$$
\frac{x^{2}}{\mathrm{r}^{2}}+\frac{(y-\mathrm{L})^{2}}{(\mathrm{r} \cdot \cos \theta)^{2}}=1
$$

Vertical coordinate of point A obtained from equation (17) and (18) is: 


$$
y=\frac{\sqrt{\mathrm{R}^{2}-\mathrm{r}^{2}} \sin \theta}{1+\cos \theta}
$$

So

$$
\begin{gathered}
\angle \mathrm{AO}_{1} \mathrm{~B}=2 \angle \mathrm{AO}_{1} \mathrm{E}=2 \operatorname{arc} \cos \left(\mathrm{O}_{1} \mathrm{E} / \mathrm{r}\right)=2 \operatorname{arc} \cos (y / \mathrm{r}) \\
\angle \mathrm{AO}_{2} \mathrm{~B}=2 \angle \mathrm{AO}_{2} \mathrm{E}=2 \arccos \left(\mathrm{O}_{2} \mathrm{E} / \mathrm{O}_{2} \mathrm{~A}\right)=2 \arccos \left(\frac{\mathrm{L}-y}{\sqrt{\mathrm{r}^{2}-y^{2}+(\mathrm{L}-y)^{2}}}\right)
\end{gathered}
$$

Arranging the equation above all, the mathematical equation of the orifice area of the ball valve is obtained.

$$
\begin{aligned}
& \mathrm{S}_{\text {Flow }}=\mathrm{r}^{2} \arccos \left(\frac{\sqrt{\mathrm{R}^{2}-\mathrm{r}^{2}} \sin \theta}{\mathrm{r}(\cos \theta+1)}\right)-\sqrt{\mathrm{r}^{2}-\frac{\left(\mathrm{R}^{2}-\mathrm{r}^{2}\right) \sin ^{2} \theta}{(\cos \theta+1)^{2}}} \sqrt{\mathrm{R}^{2}-\mathrm{r}^{2}} \sin \theta+ \\
& \mathrm{r}^{2} \cos \theta \arccos \left(\frac{\sqrt{\mathrm{R}^{2}-\mathrm{r}^{2}} \sin \theta \cos \theta}{\cos \theta+1} / \sqrt{\mathrm{r}^{2}-\left(\frac{\sqrt{\mathrm{R}^{2}-\mathrm{r}^{2}} \sin ^{2} \theta}{\cos \theta+1}\right)}\right)
\end{aligned}
$$

Table 3: The geometric details of 11/4" (DN 32) ball valve.

\section{Table 4: Results of 11/4" ball valve opening calibration.}




\section{Appendix B}

According to Fig. 16, the shaded area can be calculated as:

$$
\begin{gathered}
\mathrm{S}_{\text {Flow }}=\left(\pi \mathrm{r}^{2}\right)-\mathrm{S}_{\text {shaded }} \\
\mathrm{S}_{\text {shaded }}=\mathrm{S}_{\mathrm{MAP}}+\mathrm{S}_{\mathrm{MBP}} \\
\mathrm{S}_{\text {shaded }}=\frac{\mathrm{R}^{2}\left[\left(\angle \mathrm{MO}_{2} \mathrm{P}\right)-\sin \left(\angle \mathrm{MO}_{2} \mathrm{P}\right)\right]}{2}+\frac{\mathrm{r}^{2}\left[\left(\angle \mathrm{MO}_{1} \mathrm{P}\right)-\sin \left(\angle \mathrm{MO}_{1} \mathrm{P}\right)\right]}{2} \\
\mathrm{r}^{2}=\mathrm{R}^{2}+\mathrm{d}^{2}-2 \mathrm{R} \mathrm{d} \cos \left(\frac{\angle \mathrm{MO}_{2} \mathrm{P}}{2}\right) \\
\angle \mathrm{MO}_{2} \mathrm{P}=2 \operatorname{arc} \cos \left(\frac{\mathrm{R}^{2}+\mathrm{d}^{2}-\mathrm{r}^{2}}{2 \mathrm{Rd}}\right) \\
\mathrm{R}^{2}=\mathrm{r}^{2}+\mathrm{d}^{2}-2 \mathrm{rd} \cos \left(\frac{\angle \mathrm{MO}_{1} \mathrm{P}}{2}\right) \\
\angle \mathrm{MO}_{1} \mathrm{P}=2 \operatorname{arc} \cos \left(\frac{\mathrm{r}^{2}+\mathrm{d}^{2}-\mathrm{R}^{2}}{2 \mathrm{rd}}\right)
\end{gathered}
$$

Arranging the equation above all,

$$
\begin{aligned}
\mathrm{S}_{\text {shaded }} & =\frac{\mathrm{R}^{2}\left[2 \arccos \left(\frac{\mathrm{R}^{2}+\mathrm{d}^{2}-\mathrm{r}^{2}}{2 \mathrm{Rd}}\right)-\sin \left(2 \arccos \left(\frac{\mathrm{R}^{2}+\mathrm{d}^{2}-\mathrm{r}^{2}}{2 \mathrm{Rd}}\right)\right)\right]}{2} \\
+ & \frac{\mathrm{r}^{2}\left[2 \arccos \left(\frac{\mathrm{r}^{2}+\mathrm{d}^{2}-\mathrm{R}^{2}}{2 \mathrm{rd}}\right)-\sin \left(2 \arccos \left(\frac{\mathrm{r}^{2}+\mathrm{d}^{2}-\mathrm{R}^{2}}{2 \mathrm{rd}}\right)\right)\right]}{2}
\end{aligned}
$$


Fig. 16: Orifice area of gate valve: (a) Longitudinal-section of a gate valve and its coordinate system (b) Projection of orifice area on $x-y$ plane.

Table 5: The geometric details of 1/1/4" (DN 32) gate valve.

The distance " $h$ " was found after the calculation of "d" for a given flow area

$$
\mathrm{h}=(\mathrm{R}+\mathrm{r})-\mathrm{d}
$$

Table 6: Results of 1/1/" gate valve opening calibration. 
References

[1] Morris, S. D., 1996, "Liquid flow through safety valves: Diameter ratio effects on discharge coefficients, sizing and stability," Journal of Loss Prevention in the Process Industries., 9(3), pp. 211-224.

[2] Kim, S. W., and No, H. c., 2001, "Subcoold water critical pressure and critical flow rate in a safety valve," International Journal of Heat and Mass Transfert., 44, pp. 4567-4577.

[3] Merati, P., Macelt, M. J., and Erickson, R. B., 2001, "Flow Investigation Around a V-Sector Ball Valve," ASME Journal of Fluids Engineering., 123, pp. 662-671.

[4] Chern, M. J., and Wang, C. C., 2004, “Control of Volumetric Flow-Rate of Ball Valve Using V-Port,” ASME Journal of Fluids Engineering., 126, pp. 471-481.

[5] American National Standards Institute/Instrument Society of America., 1996, “Control valve capacity test procedure," New York, ANSI/ISA 75.02.

[6] Chern, M. J., Wang, C. C., and Ma, C. H., 2007, "Performance test and flow visualization of ball valve," Experimental Thermal and Fluid Science., 31, pp. 505-512.

[7] Baoling, C., Zhe, L., Zuchao, Z., Huijie, W., and Guangfei, M., 2017, “Influence of opening and closing process of ball valve on external performance and internal flow characteristics," Experimental Thermal and Fluid Science., 80, pp. 193-202. 
[8] Lin, Z., Ma, C., Xu, H., Li, X., Cui, B., and Zhu, Z., 2017, "Numerical and experimental studies on hydrodynamic characteristics of sleeve regulating valves," Flow Measurement and Instrumentation., 53, pp. 279-285.

[9] Moujaes, S. F., and Jagan, R., 2008, “3D CFD Predictions and Experimental Comparisons of Pressure Drop in a Ball Valve at Different Partial Openings in Turbulent Flow," Journal of Energy Engineering., 134, pp. 24-28.

[10] Wang, D., and Bai, C., 2018, "The parametric modeling of local resistance and pressure drop in a rotary ball valve,” ASME Journal of Fluids Engineering., 140, pp. 1-11.

[11] Shi, X., Lü, H., Zhang, K., Zhu, D., Sun, B., and Cao, B,. 2013, “Analysis on resistance characteristics and flow mechanism of PVC ball valve," Transactions of the Chinese Society of Agricultural Engineering., 29(4), pp. 95-101.

[12] TREMBLAY, P. E., and ANDREWS, D. G., 1974, "Hydraulic Characteristics of a Valve in Two-Phase Flow," The Canadian Journal of Chemical Engineering., 52, pp. 433-437.

[13] Sookprasong, P., Brill, J. P., and Schmidt, Z., 1986, "Two-Phase Flow in Piping Components,” Journal of Energy Resources Technology., 108, pp. 197-201.

[14] Ching-Yi, H.J., and Rajinder, P., 1998. "Pressure Losses in Globe and Gate Valves during Two-Phase Oil/Water Emulsion Flow," Industrial \& Engineering Chemistry Research., 37, pp. 636-642. 
[15] Van Lookeren Campagne, C., Nicodemus, R., de Bruin, G. J., and Lohse, D., 2002, “A Method for Pressure Calculation in Ball Valves Containing Bubbles," ASME Journal of Fluids Engineering., 124, pp. 765-771.

[16] Alimonti, C., Falcone, G., and Bello, O., 2010, "Two-phase flow characteristics in multiple orifice valves," Experimental Thermal and Fluid Science., 34, pp. 1324-1333.

[17] Alimonti, C., 2014, "Experimental characterization of globe and gate valves in vertical gasliquid flows," Experimental Thermal and Fluid Science., 54, pp. 259-266.

[18] Chisholm, D., 1983, Two-phase Flow in Pipelines and Heat Exchangers, Longman Group Ed, London.

[19] Zeghloul, A., Azzi, A., Saidj, F., Messilem, A., and Azzopardi, B. J., 2017, "Pressure Drop Through Orifices for Single and Two-Phase Vertically Upward Flow - Implication for Metering,” ASME Journal of Fluids Engineering., 139, pp. 1-12.

[20] Zeghloul, A., Azzi, A., Hasan, A., and Azzopardi, B. J., 2017, "Behavior and pressure drop of an upwardly two-phase flow through multi-hole orifices," Journal of Mechanical Engineering Science., 0(0), pp. 1-19.

[21] Fossa, M., Guglielmini, G., and Marchitto, A., 2006, "Two-phase flow structure close to orifice contractions during horizontal intermittent flows," International Communications in Heat and Mass Transfer., 33, pp. 698-708. 
[22] Saidj, F., Hasan, A., Bouyahiaoui, H., Zeghloul, A., and Azzi, A., 2018, “Experimental study of the characteristics of an upward two-phase slug flow in a vertical pipe," Progress in Nuclear Energy., 108, pp. 428-437.

[23] Zeghloul, A., Azzi, A., Saidj, F., Azzopardi, B. J., and Hewakandamby, B., 2015, "Interrogating the effect of an orifice on the upward two-phase gas-liquid flow behavior," International Journal of Multiphase Flow., 74, pp. 96-105.

[24] International Organization for Standardization., 1991, "Measurement of fluid flow by means of pressure differential devices, part 1: Orifice plates, nozzles and Venturi tubes inserted in circular cross-section conduits running full," Geneva, Switzerland, Standard No. ISO 51671.

[25] Miller, D., 1987, Internal Flow Systems, 2nd ed., BHRA The Fluid Engineering Centre, Cranfield, Bedford, UK.

[26] Idel'chik, I., Malyavskayafs, G., Martynenko, O., and Fried, E., 1994, Handbook of hydraulic resistances, 3rd ed., CRC Press, Boca Raton, FL.

[27] Simpson, H., Rooney, D., and Grattan, E., 1983, “Two-phase flow through gate valves and orifice plates,” International Conference on Physical Modelling of Multiphase Flow, Coventry, UK.

[28] Morris, S., 1985, “Two-phase pressure drop across valves and orifice plates," European Two Phase Flow Group Meeting, Marchwood Engineering Laboratories, Southampton, UK. 
[29] Watson, G., Vaughan, V., and McFarlane, M., 1967, “Two-phase pressure drop with a sharpedged orifice," NEL Report No. 290.

[30] Collins, D. B., and Gacesa, M., 1971, "Measurement of steam quality in two-phase up flow with venturis and orifice plates,” ASME J. Basic. Eng., 93(11), pp. 11-21.

[31] James, R., 1965, "Metering of steam-water two-phase flow by sharp-edged orifices," Proceedings of the Institution of Mechanical engineers., 180, pp. 549-572.

[32] Govan, A. H., 1988, “A Note on Statistical Methods for Comparing Measured and Calculated Values,” United Kingdom Atomic Energy Authority, Report No. AERE-M3621.

[33] Abdulkadir, M., Zhao, D., Azzi, A., Lowndes I. S., and Azzopardi, B. J., 2012, “Two phase air-water flow through a large diameter vertical $180^{\circ}$ bend," Chem. Eng. Sci., 79, pp. 138152.

[34] Chul-Hwa, S., Moon, K. C., and Hee, C. N., 1998, "Measurements of void fraction by an improved multi-channel conductance void meter," Nuclear Engineering and Design., 184, pp. 269-285.

[35] Bouyahiaoui, H., Azzi, A., Zeghloul, A., Hasan, A., and Berrouk, A. S., 2018, "Experimental investigation of a vertically downward two-phase air-water slug flow," Journal of Petroleum Science and Engineering, 162, pp. 12-21. 


\section{Nomenclature:}

\section{Symbols :}

A Area of the valve orifice, $\mathrm{m}^{2}$

$\mathrm{C}_{\mathrm{d}} \quad$ Discharge coefficient

$\mathrm{C}_{\mathrm{a}} \quad$ Flow area coefficient

Cc Contraction coefficient

D Pipe diameter, $\mathrm{m}$

DN Nominal Pipe Size 'Diametre Nominal'

e Logarithmic distribution error

F Govan correction factor

K Pressure drop coefficient

$\mathrm{K}_{\mathrm{V}} \quad$ Experimental volumetric flow in $\mathrm{m}^{3} / \mathrm{h}$ or $1 / \mathrm{min}$

M Mean error

n Number of measurements in the sample

Q Volumetric flow rate measured in $\mathrm{m}^{3} / \mathrm{h}$ or in $1 / \mathrm{min}$

R Root-mean-square error

S Govan transformed standard deviation

U Mean velocity, $\mathrm{m} / \mathrm{s}$

Uls Superficial liquid velocity, $\mathrm{m} / \mathrm{s}$

Ugs Superficial gas velocity, $\mathrm{m} / \mathrm{s}$

$x \quad$ Mass flow quality

X Lockhart-Martinelli parameter

$\mathrm{Z} \quad$ Distance from the valve, $\mathrm{m}$

\section{Greek Letters :}

$\Delta \mathrm{P} \quad$ Pressure drop through the valve, $\mathrm{Pa}$

$\begin{array}{ll}\sigma & \text { Orifice open area, } \sigma=\left(\frac{\mathrm{d}_{\text {orifice }}}{D_{\text {pipe }}}\right)^{2} \\ \sigma_{v c} & \text { Vena contracta, } \sigma_{v c}=\left(\frac{\mathrm{d}_{v c}}{D_{\text {pipe }}}\right)^{2} \\ \rho & \text { Fluid density, } \mathrm{kg} / \mathrm{m}^{3}\end{array}$


$\beta \quad$ Diameter ratio of the orifice to that of the pipe, $d / D$

$\gamma \quad$ Relative density with respect to water (liquids)

$\Phi_{\mathrm{LO}}^{2} \quad$ Two-phase multiplier

\section{Subscripts :}

contraction

exp experimental

g Gas

$l \quad$ liquid

LO liquid only

mod model

$S P \quad$ single-phase

TP two-phase flow

w Water

Abbreviations :

LabVIEW Laboratory Virtual Instrument Engineering Workbench

PMMA Polymethylmethacrylate (Acrylic) 


\section{Figure Captions List}

\begin{tabular}{|c|c|}
\hline Fig. 1 & A Schematic diagram of the experimental test facility. \\
\hline Fig. 2 & Gate and ball valve used in the experiments. \\
\hline Fig. 3 & Purging system arrangement used in the pressure drop (DP) measurements. \\
\hline Fig. 4 & Valve characteristic curves; Valve coefficient vs. opening percentage. \\
\hline Fig. 5 & Flow resistance coefficient vs. opening of the $1 \frac{1}{4} 4$ " DN gate valve. \\
\hline Fig. 6 & Flow resistance coefficient vs. opening of the $1 \frac{1 / 4 "}{}$ DN ball valve. \\
\hline Fig. 7 & Single-phase pressure drop of the gate valve. \\
\hline Fig. 8 & Single-phase pressure drop of the ball valve. \\
\hline Fig. 9 & $\begin{array}{l}\text { Variation of the pressure drop, } \Delta \mathrm{P}_{\mathrm{TP}} \text { with } \mathrm{U}_{\mathrm{gs}} \text { at different values of } \mathrm{U}_{\mathrm{ls}} \text { and } \\
\text { different opening areas of the gate valve. }\end{array}$ \\
\hline Fig. 10 & $\begin{array}{l}\text { Variation of the pressure drop, } \Delta \mathrm{P}_{\mathrm{TP}} \text { with } \mathrm{U}_{\mathrm{gs}} \text { at different values of } \mathrm{U}_{\mathrm{ls}} \text { and } \\
\text { different opening areas of the ball valve. }\end{array}$ \\
\hline Fig. 11 & $\begin{array}{l}\text { Comparison between experimental and predicted two-phase flow pressure } \\
\text { drop multiplier for different gate valve and ball valve openings. }\end{array}$ \\
\hline Fig. 12 & $\begin{array}{l}\text { Valve two-phase flow pressure drop multiplier versus the upstream liquid } \\
\text { holdup, G.V. (gate valve), B.V (ball valve). }\end{array}$ \\
\hline Fig. 13 & Comparison between predicted \& experimental two-phase flow multiplier. \\
\hline Fig. 14 & $\begin{array}{l}\text { Ball valve orifice area, (a) ball valve longitudinal-section, (b) } x-y \text { projection } \\
\text { plane of the ball valve orifice area }[10] .\end{array}$ \\
\hline Fig. 15 & Details of the ball valve orifice area in $\mathrm{x}-\mathrm{y}$ projection plane [10]. \\
\hline Fig. 16 & $\begin{array}{l}\text { Orifice area of gate valve: (a) Longitudinal-section of a gate valve and its } \\
\text { coordinate system (b) Projection of orifice area on x-y plane. }\end{array}$ \\
\hline
\end{tabular}




\section{Table Captions List}

\begin{tabular}{|l|l|}
\hline Table 1 & $\begin{array}{l}\text { Two-phase flow correlations of pressure drop multiplier in orifices and valves } \\
{[19] .}\end{array}$ \\
\hline Table 2 & $\begin{array}{l}\text { Comparison of the experimental two-phase flow multiplier data and the } \\
\text { selection of correlations. }\end{array}$ \\
\hline Table 3 & The geometric details of 11/4" (DN 32) ball valve. \\
\hline Table 4 & Results of 11/4" ball valve opening calibration. \\
\hline Table 5 & The geometric details of 11/4" (DN 32) gate valve. \\
\hline Table 6 & Results of 11/4" gate valve opening calibration. \\
\hline
\end{tabular}




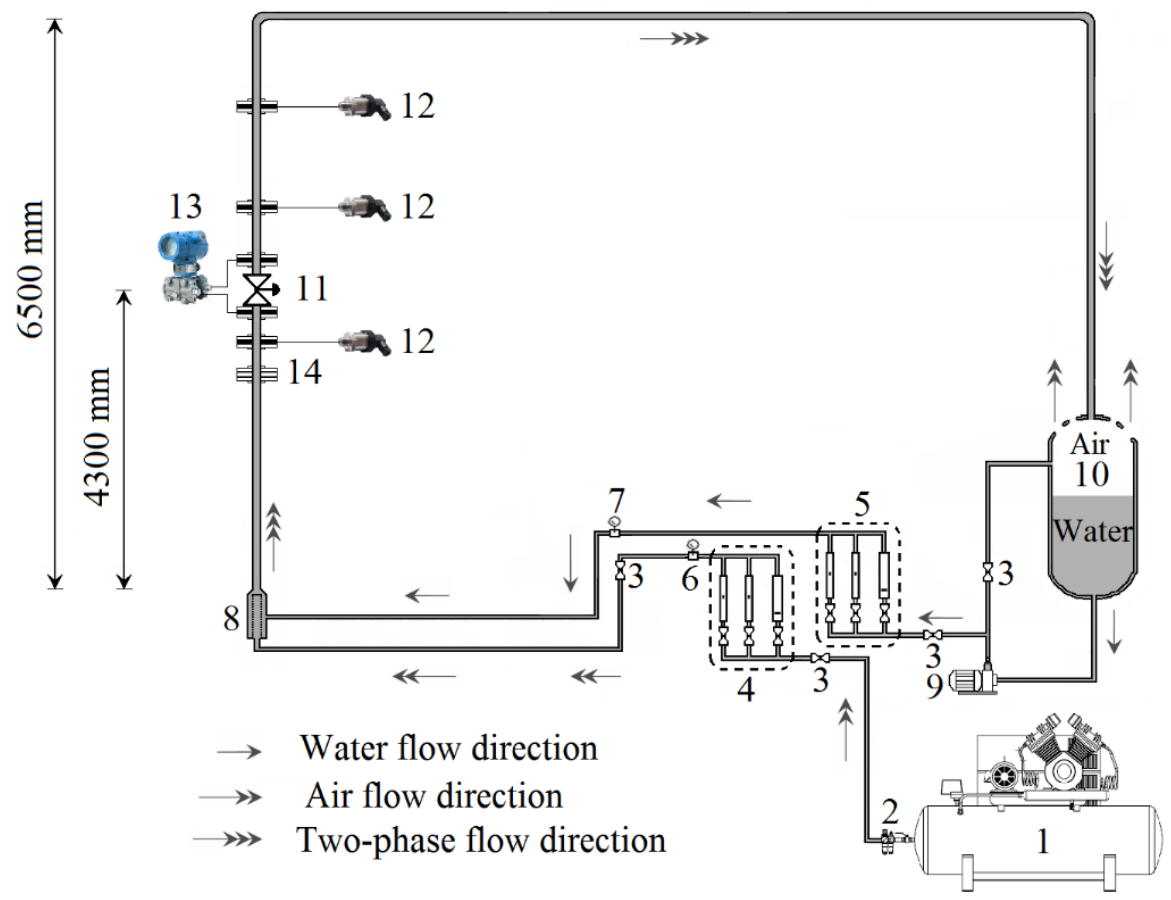

1-Compressor, 2-regulator, 3-Valve, 4-Air Flow-meters, 5-Water flow-meters, 6-Manometer, 7Thermometer, 8-Mixer, 9-Pump, 10-Tank/Separator, 11-Tested valve, 12-Absolute pressure transducers, 13-Differential pressure transducer, 14-Conductance probe.

Fig. 1. A Schematic diagram of the experimental test facility 
a) gate valve

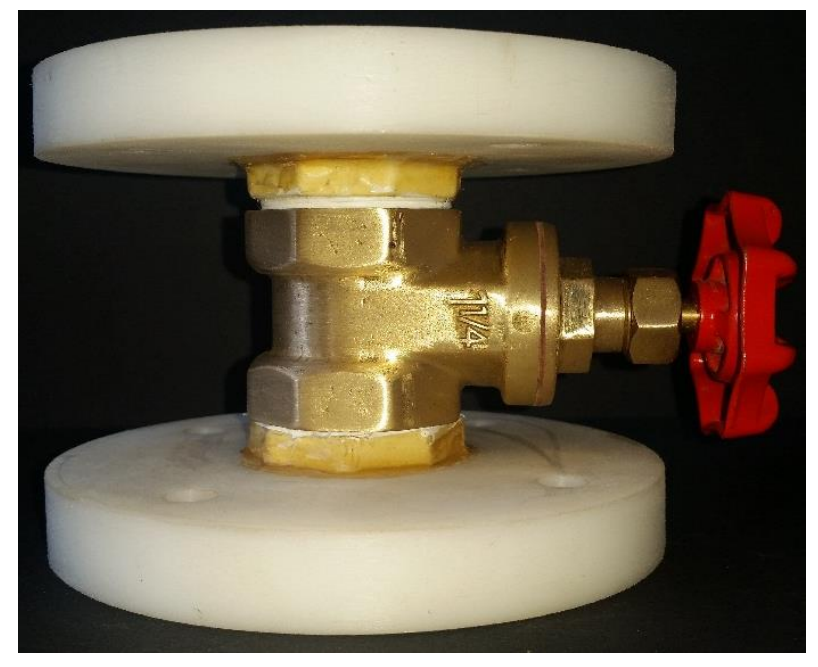

b) ball valve

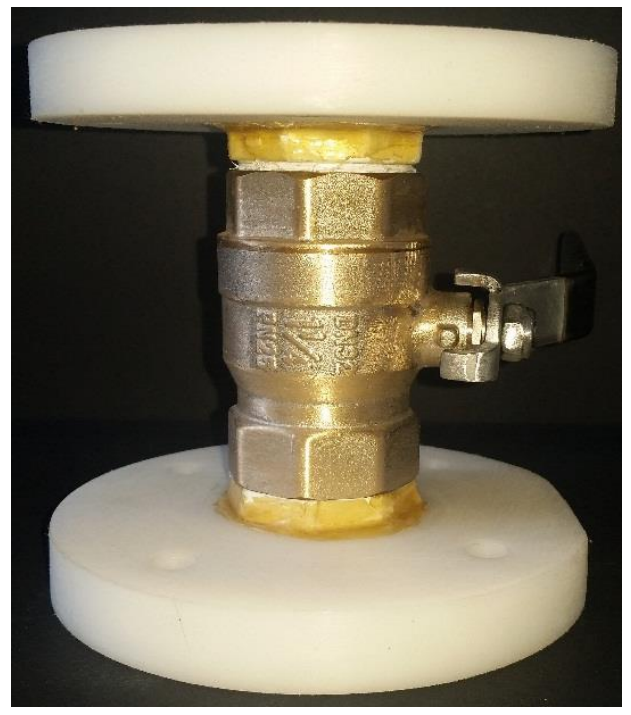

Fig. 2. Gate and ball valve used in the experiments 


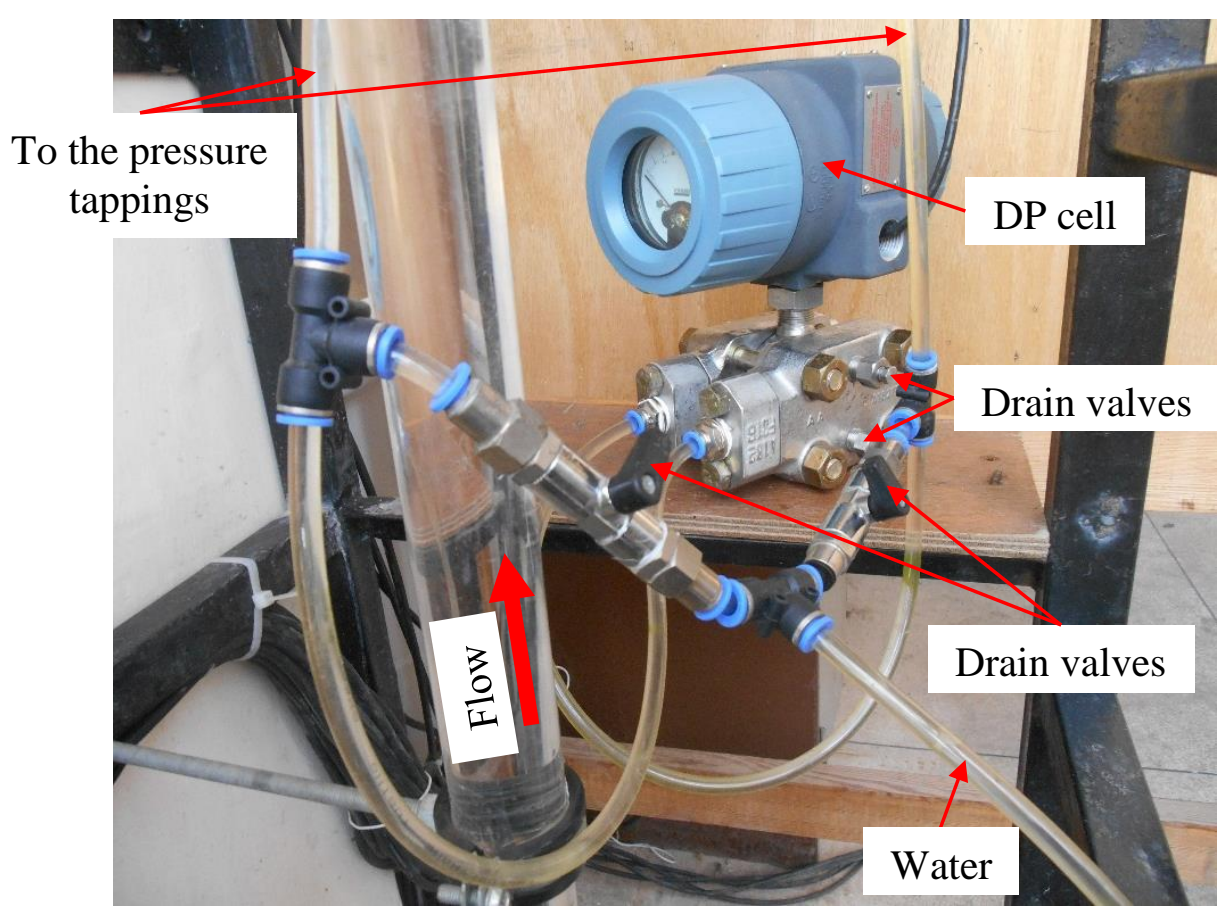

Fig. 3. Purging system arrangement used in the pressure drop (DP) measurements 


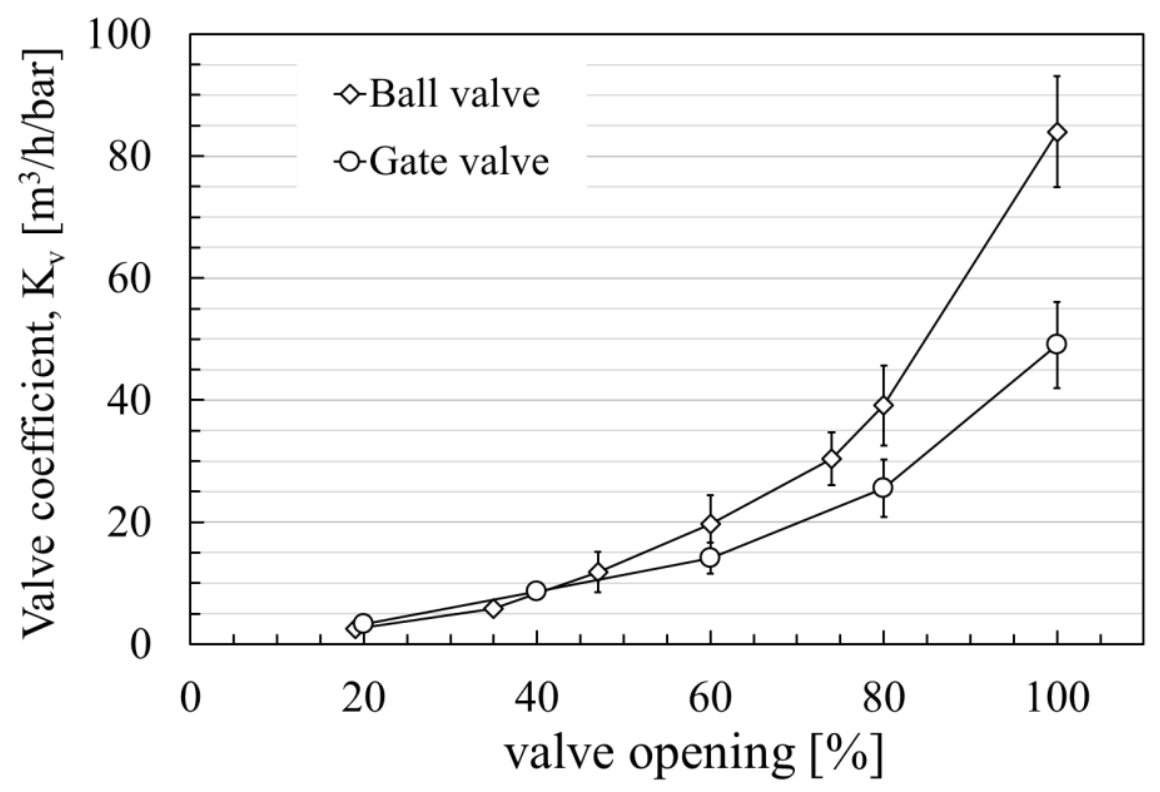

Fig. 4. Valve characteristic curves; Valve coefficient vs. opening percentage 


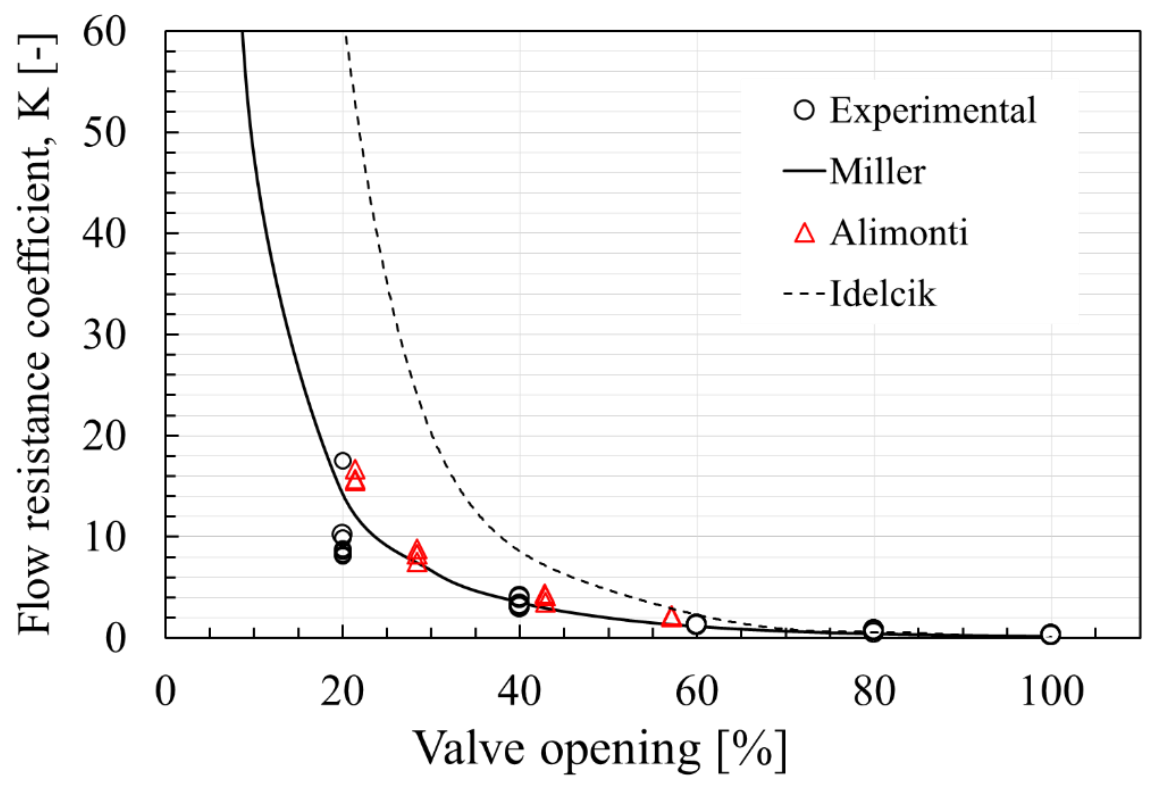

Fig. 5. Flow resistance coefficient vs. opening of the $1 \frac{1 / 4}{4}$ DN gate valve 


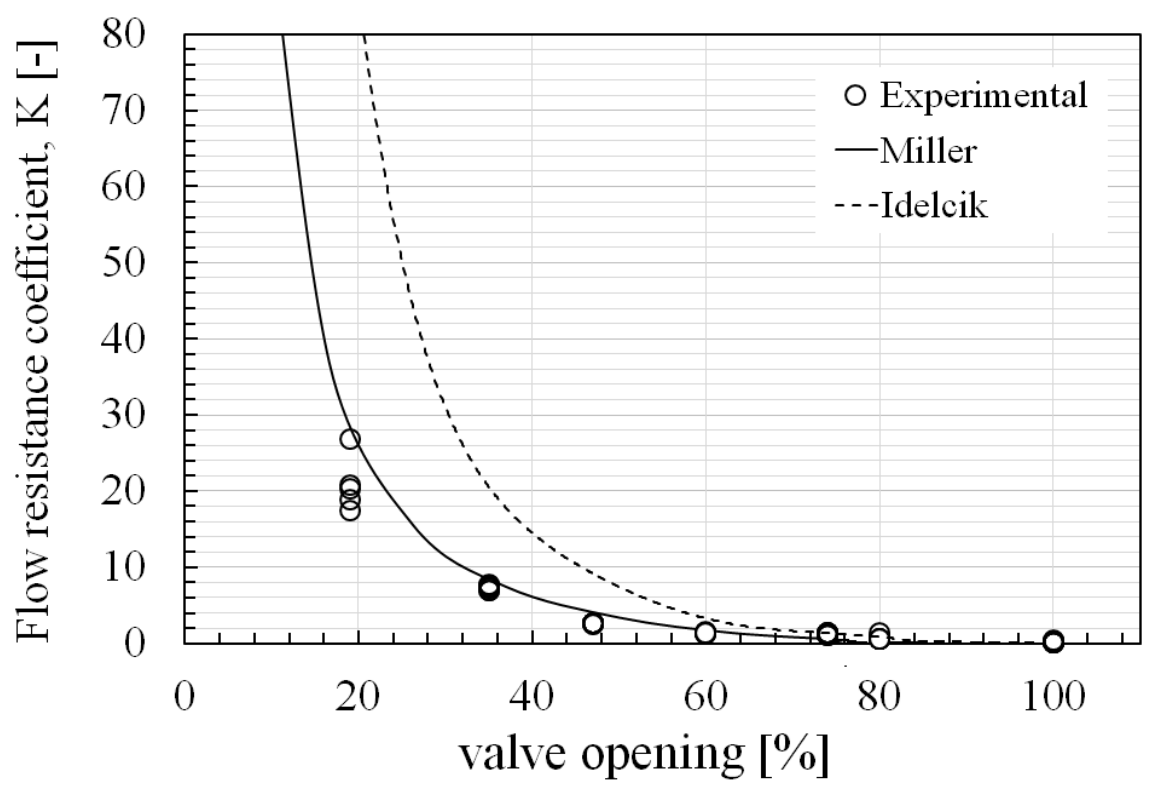

Fig. 6. Flow resistance coefficient vs. opening of the $1 \frac{1 / 4}{4}$ DN ball valve 


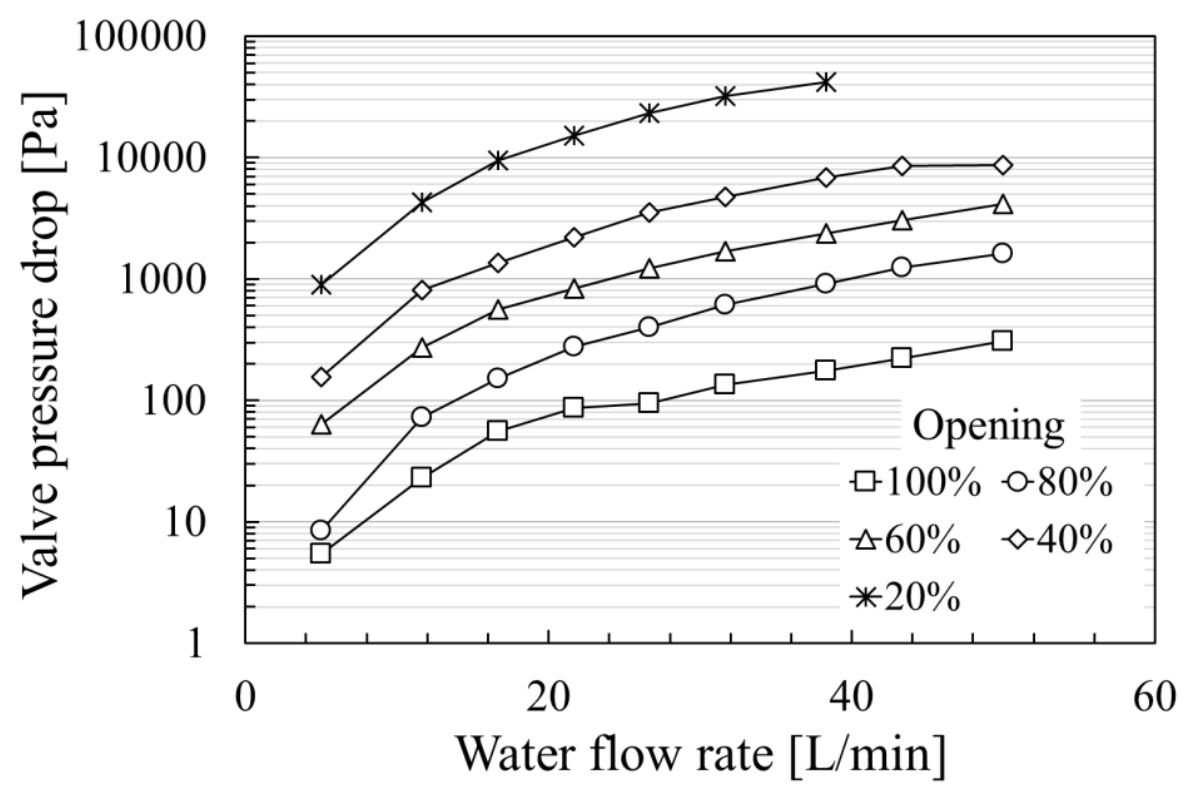

Fig. 7. Single-phase pressure drop of the gate valve 


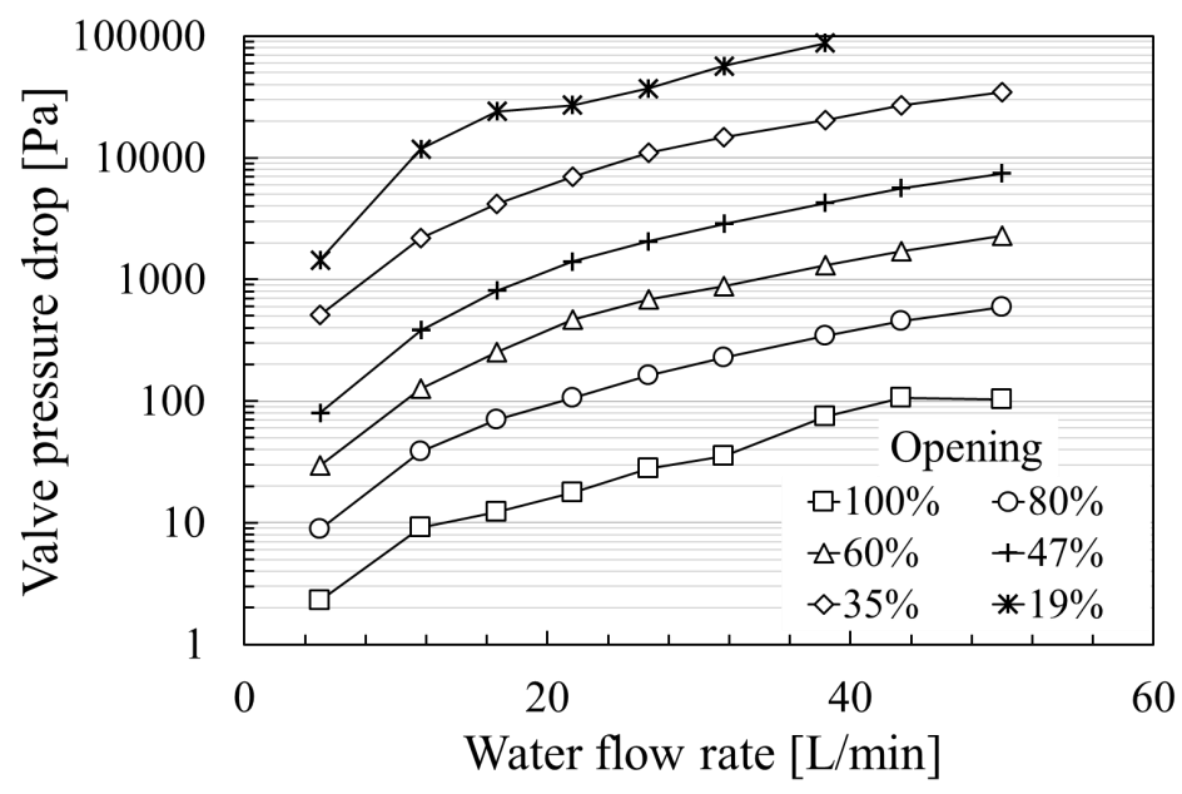

Fig. 8. Single-phase pressure drop of the ball valve. 
a) Opening of the gate valve: $100 \%$.

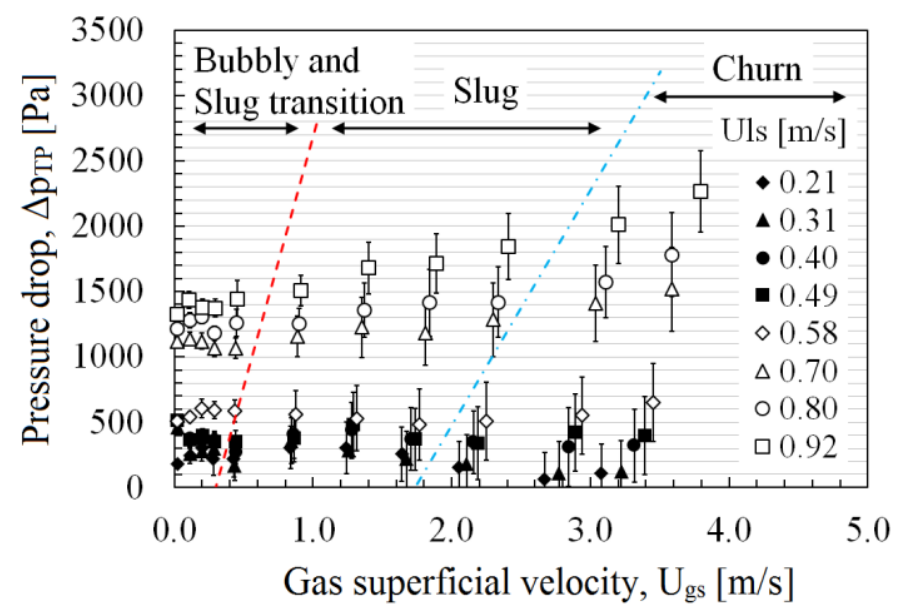

c) Opening of the gate valve: $60 \%$.

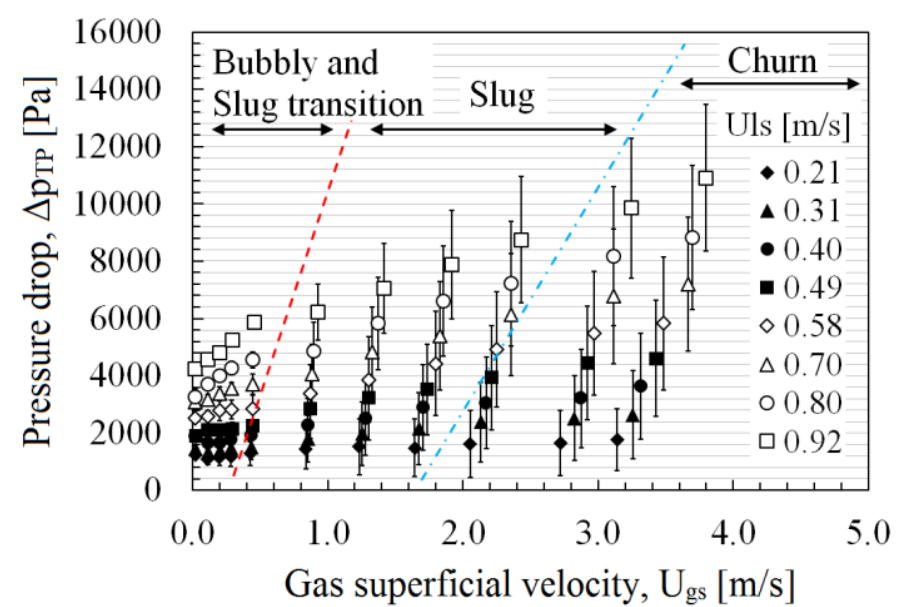

e) Opening of the gate valve: $20 \%$.

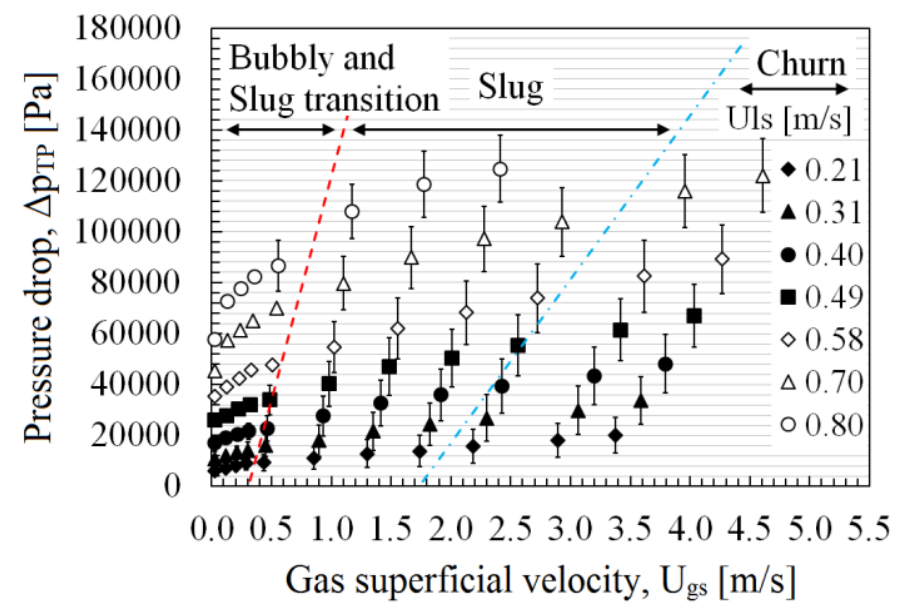

\section{b) Opening of the gate valve: $80 \%$.}

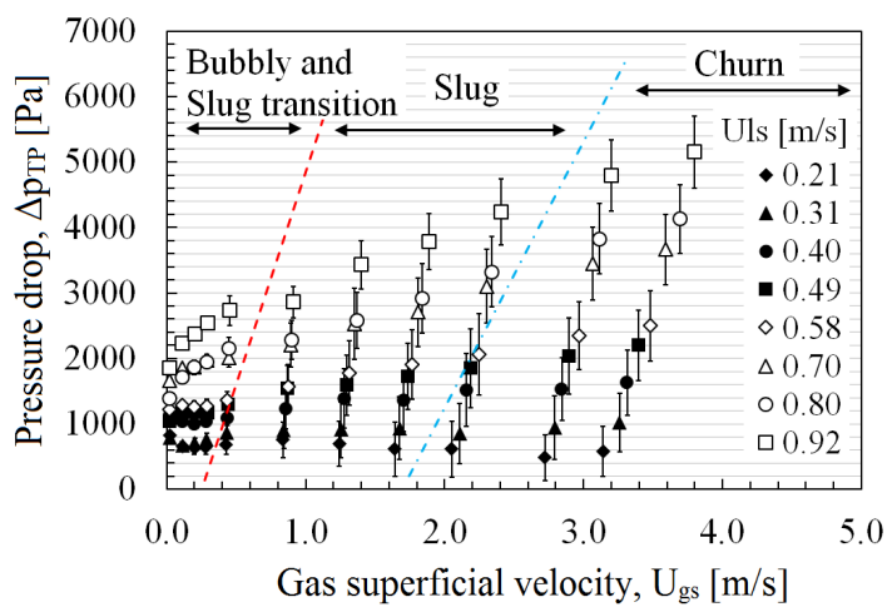

d) Opening of the gate valve: $40 \%$.

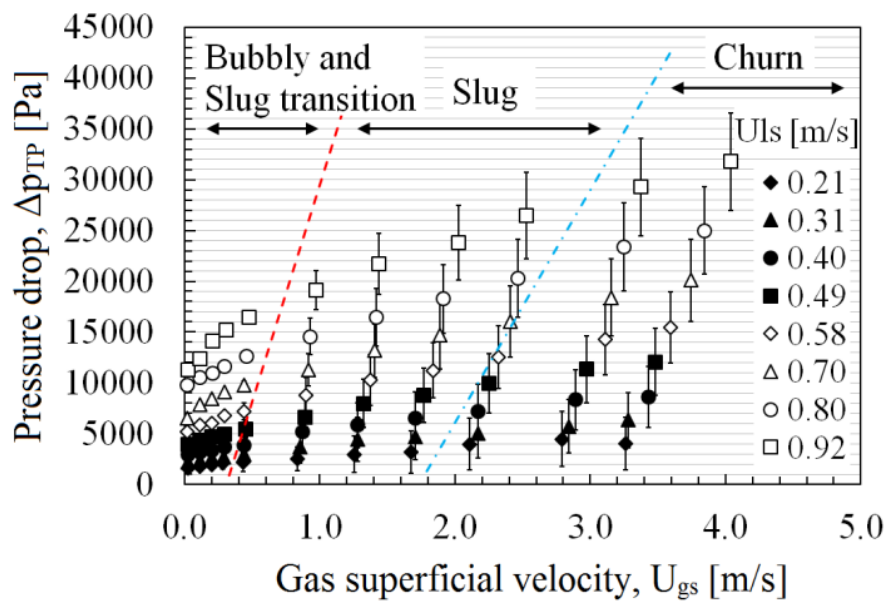

Fig. 9. Variation of the pressure drop, $\Delta \mathrm{P}_{\mathrm{TP}}$ with $\mathrm{U}_{\mathrm{gs}}$ at different values of Uls and different opening areas of the gate valve. 
a) Opening of the ball valve: $100 \%$.

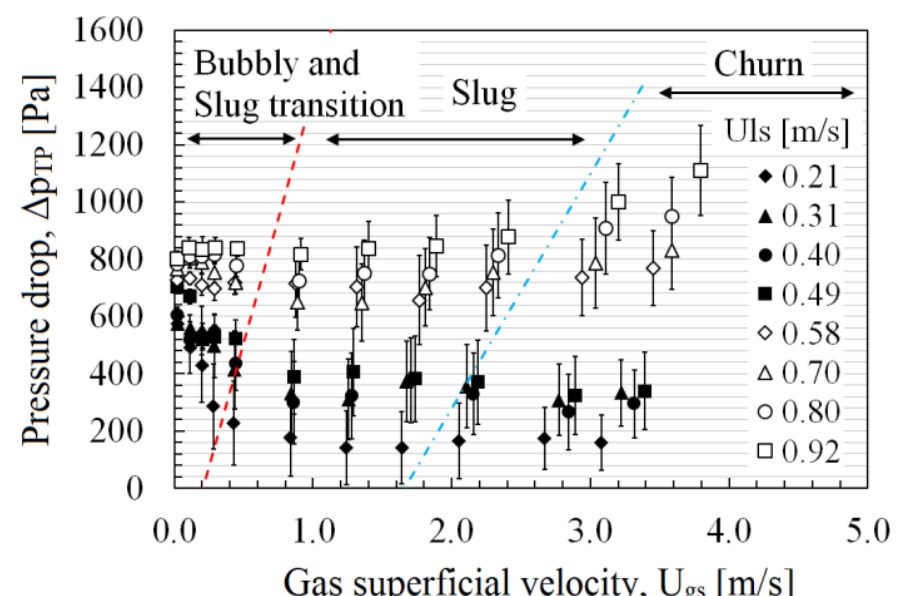

c) Opening of the ball valve: $60 \%$.

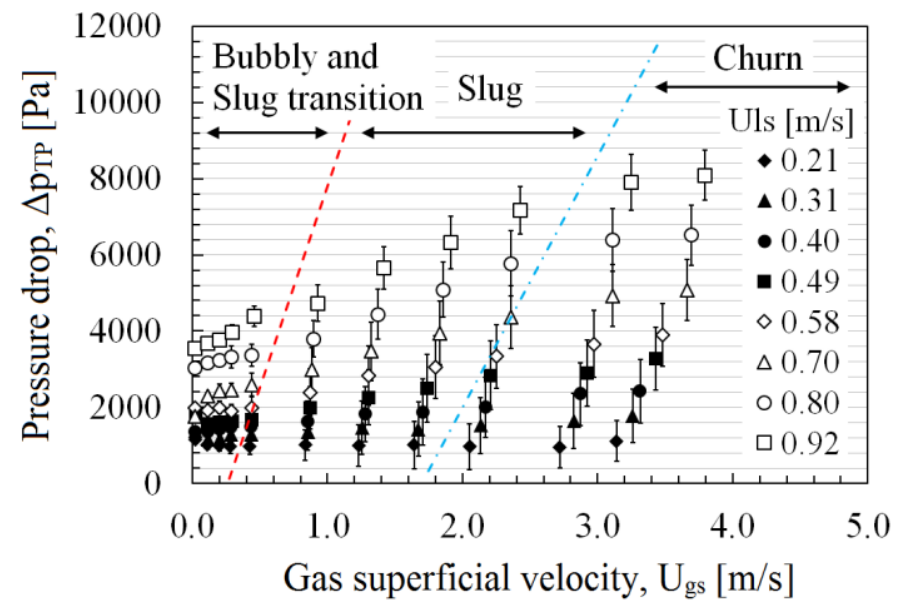

e) Opening of the ball valve: $35 \%$.

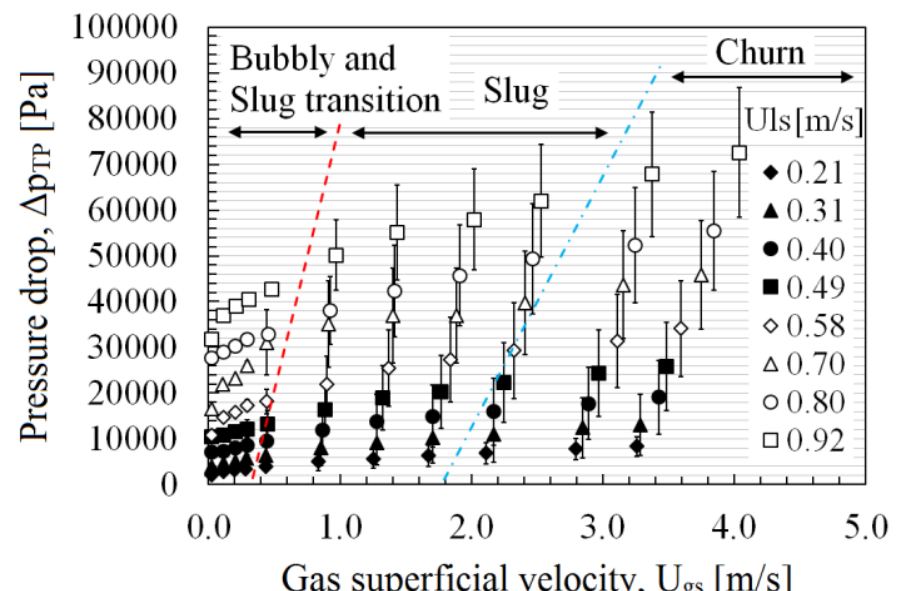

b) Opening of the ball valve: $80 \%$.

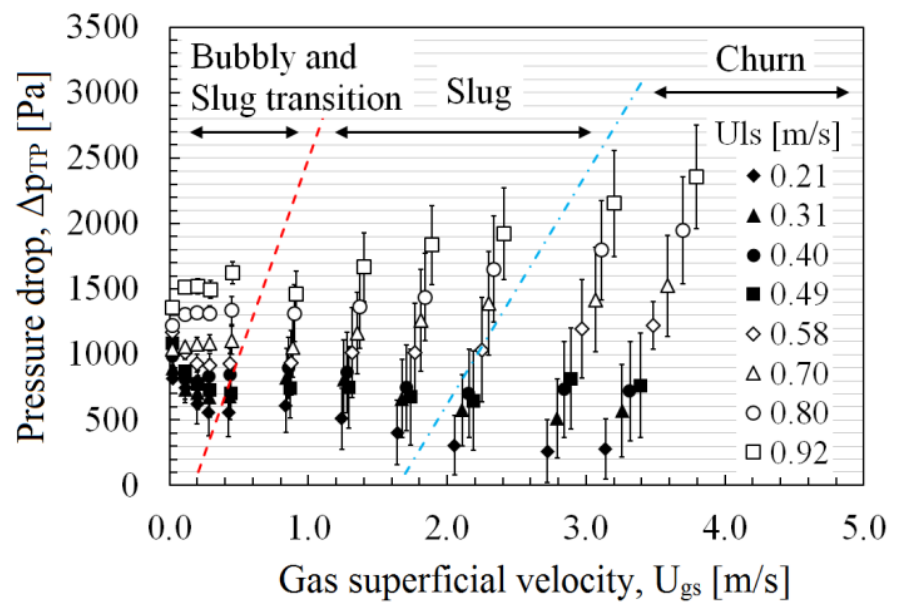

d) Opening of the ball valve: $47 \%$.

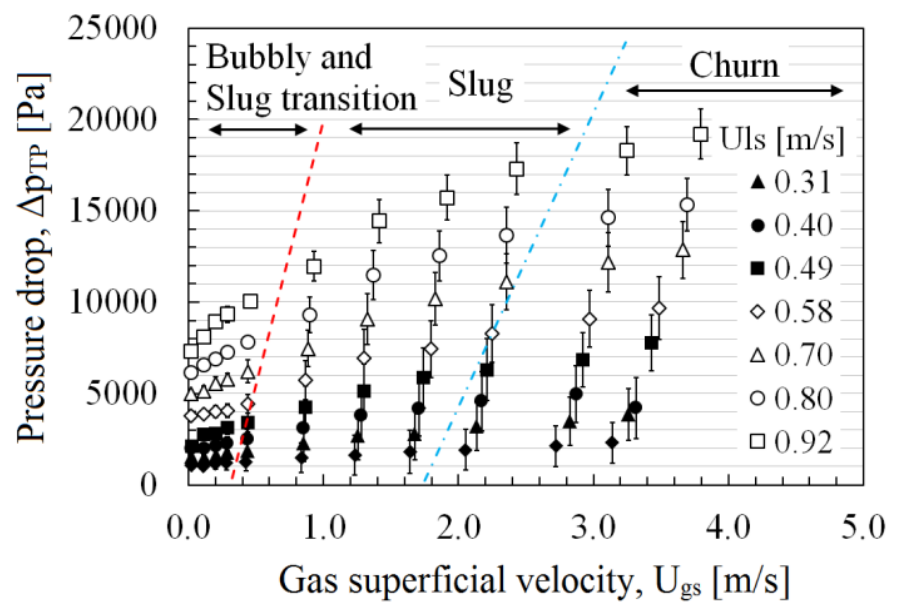

f) Opening of the ball valve: $19 \%$.

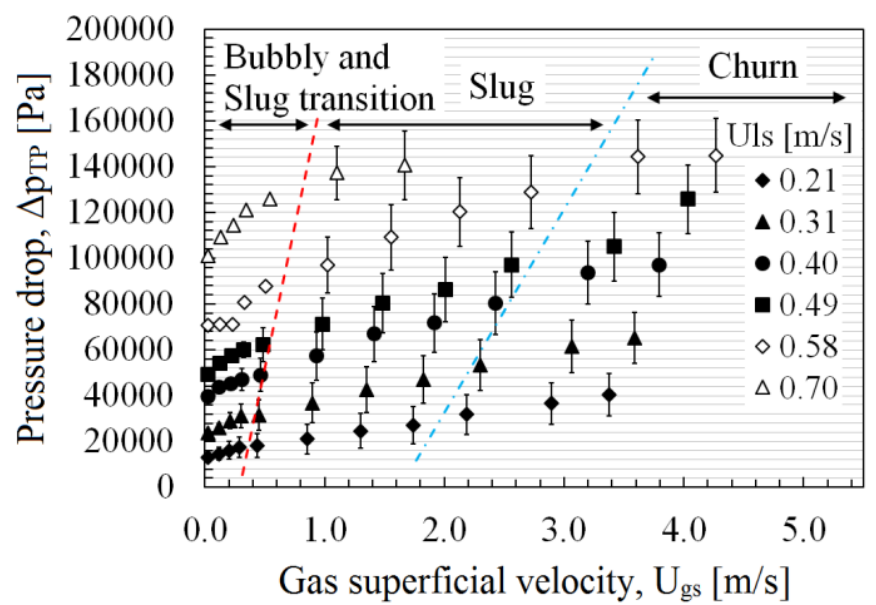

Fig. 10. Variation of the pressure drop, $\Delta \mathrm{P}_{\mathrm{TP}}$ with $\mathrm{U}_{\mathrm{gs}}$ at different values of Uls and different opening areas of the ball valve 
a)

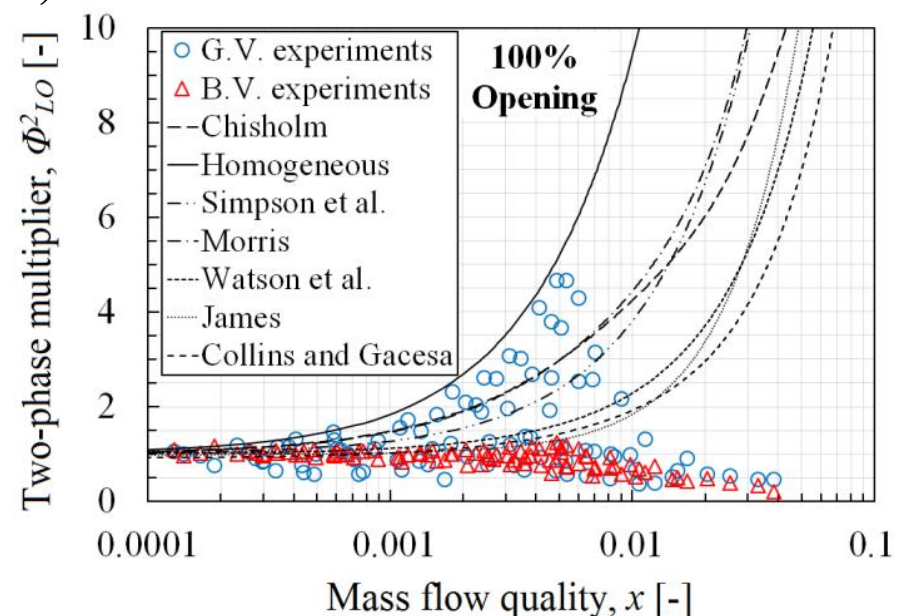

c)

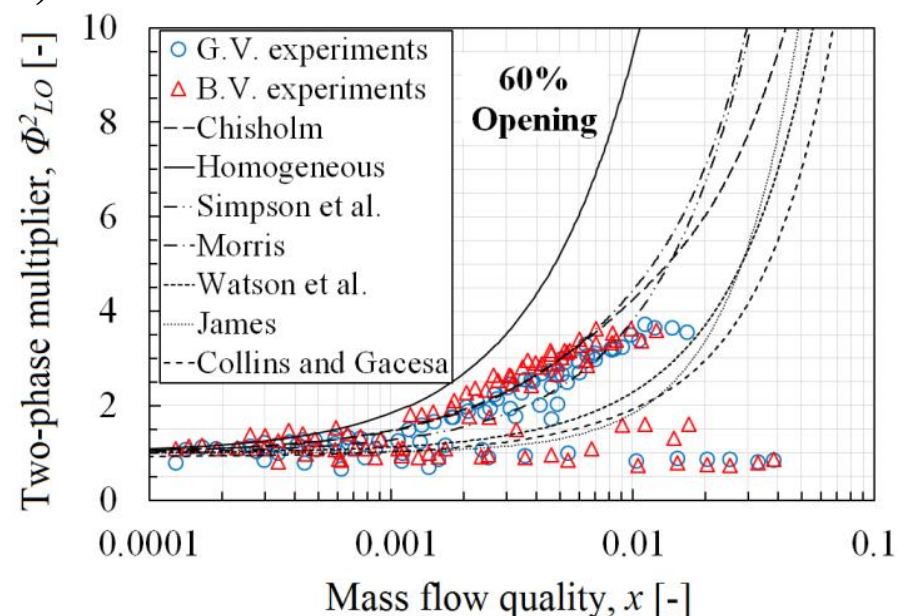

e)

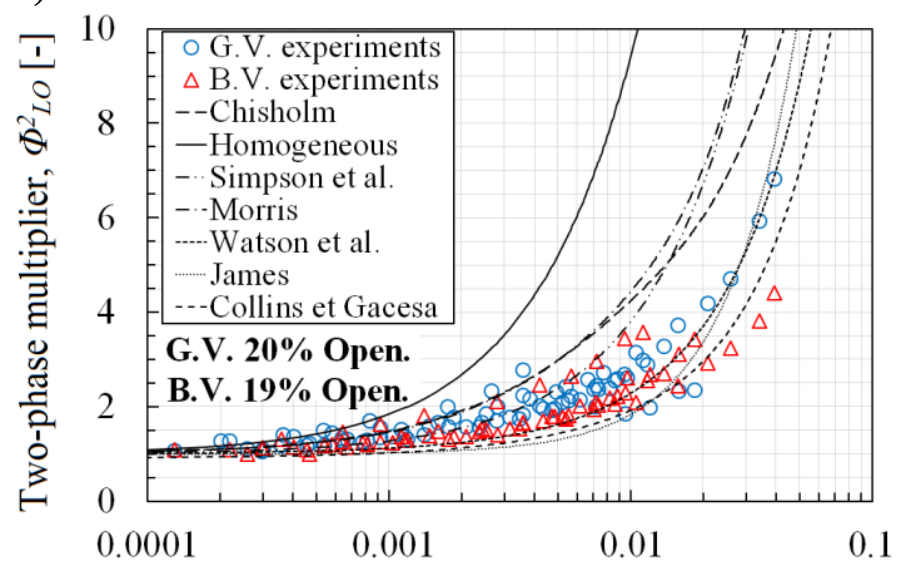

b)

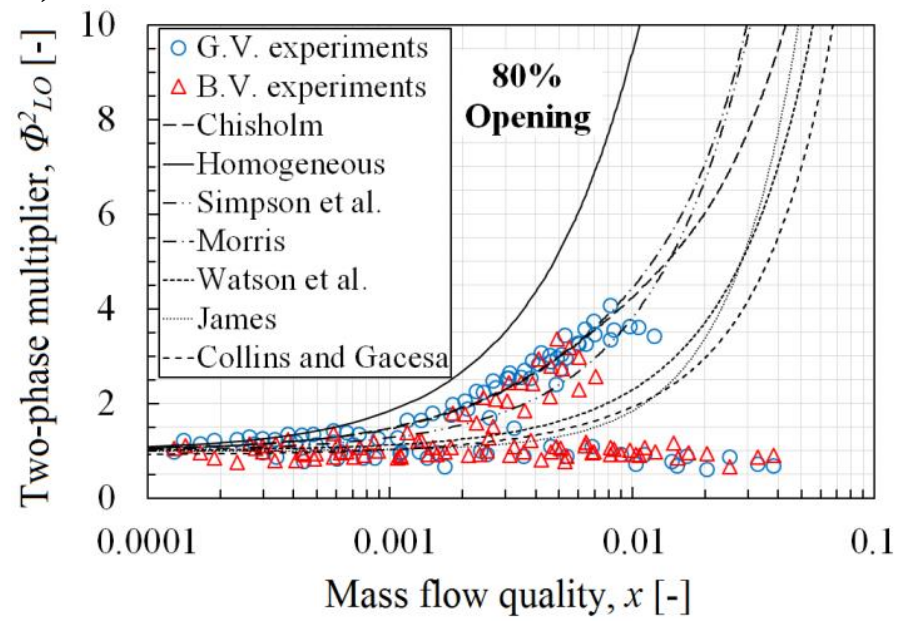

d)

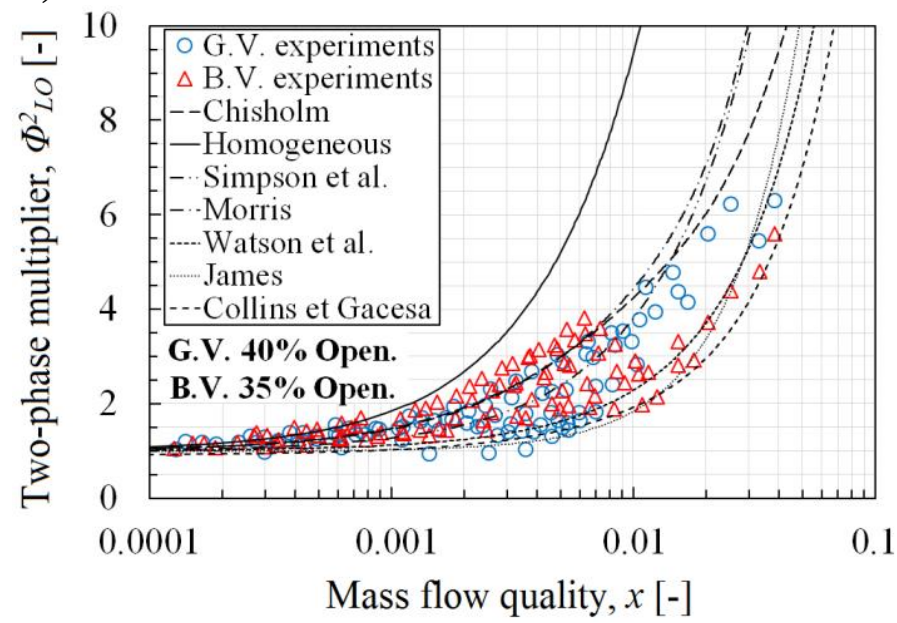

Mass flow quality, $x[-]$

Fig. 11. Comparison between experimental and predicted two-phase flow pressure drop multiplier for different gate valve and ball valve openings. 
a)

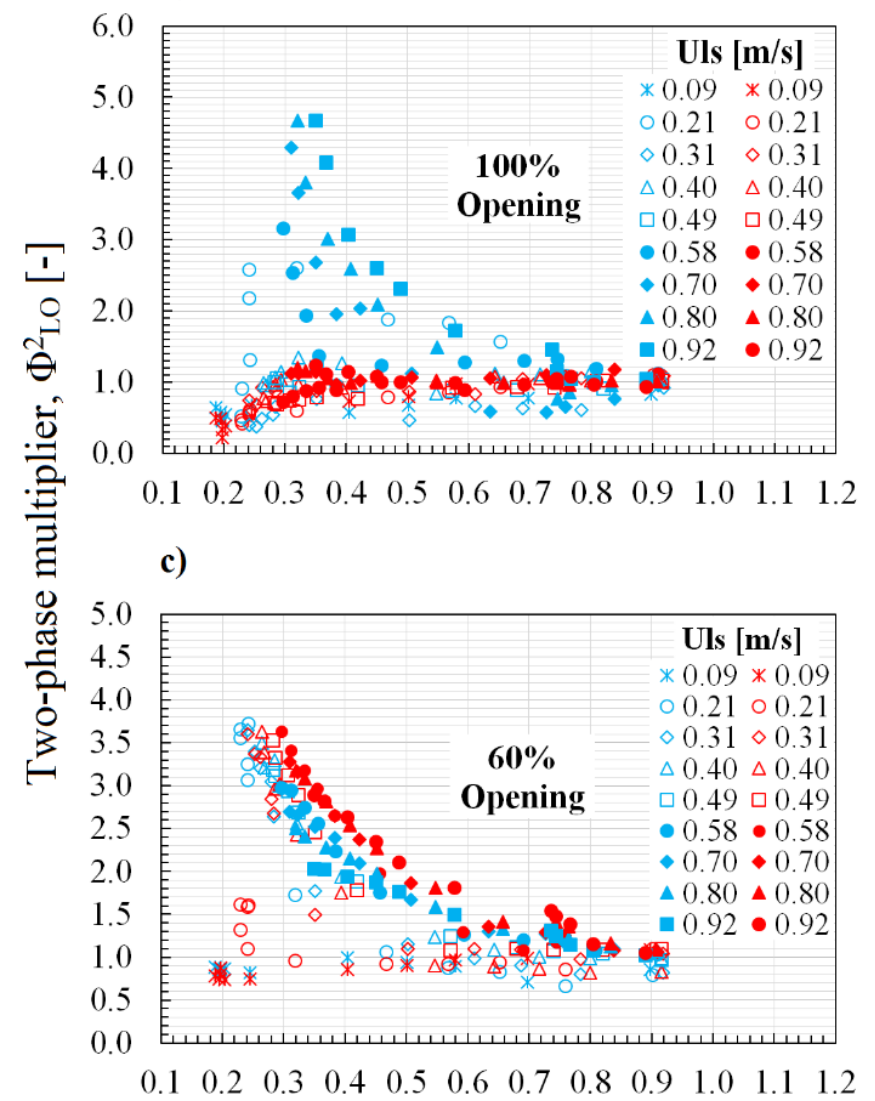

b)
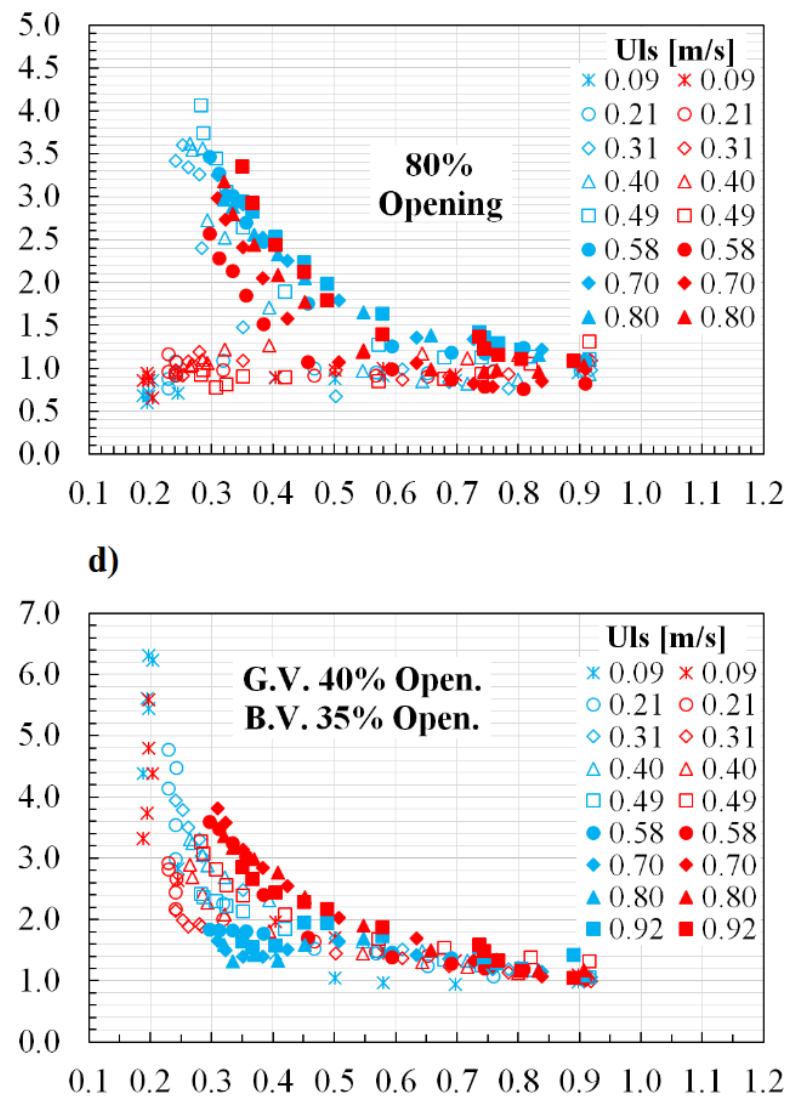

e)

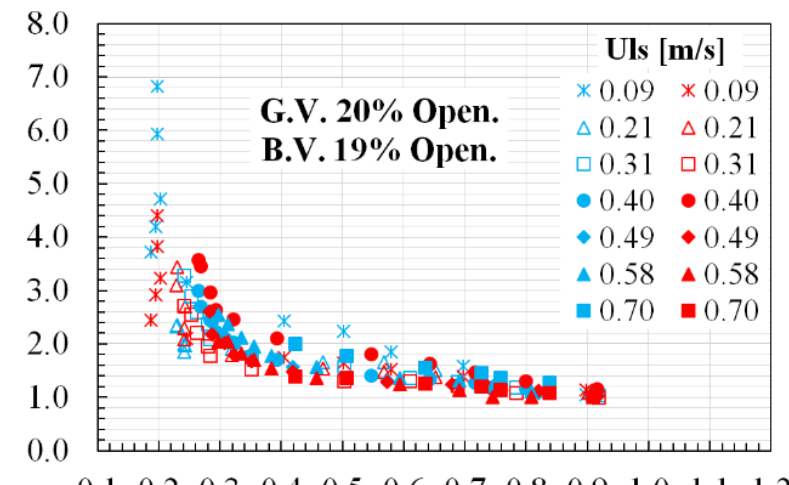

$\begin{array}{lllllllllllll}0.1 & 0.2 & 0.3 & 0.4 & 0.5 & 0.6 & 0.7 & 0.8 & 0.9 & 1.0 & 1.1 & 1.2\end{array}$

Liquid holdup, $\beta[-]$

Fig. 12. Valve two-phase flow pressure drop multiplier versus the upstream liquid holdup, G.V.

(gate valve), B.V (ball valve). 
Gate valve
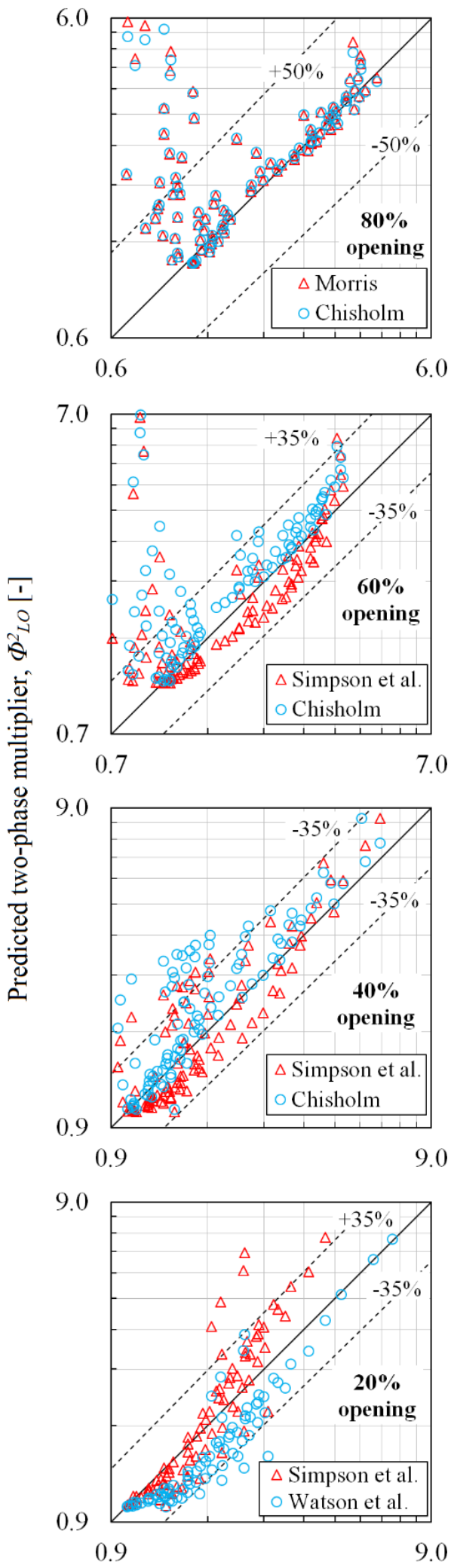

Ball valve

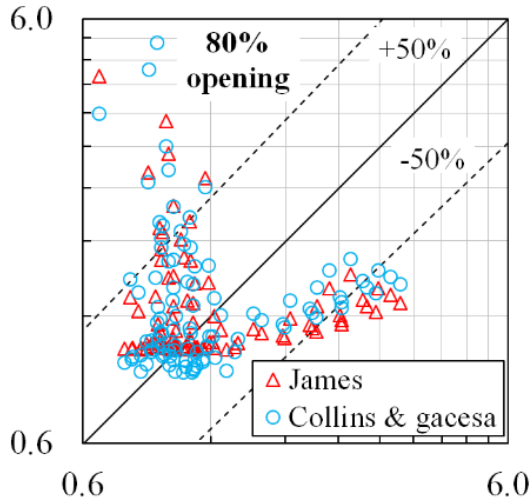

7.0

0.7

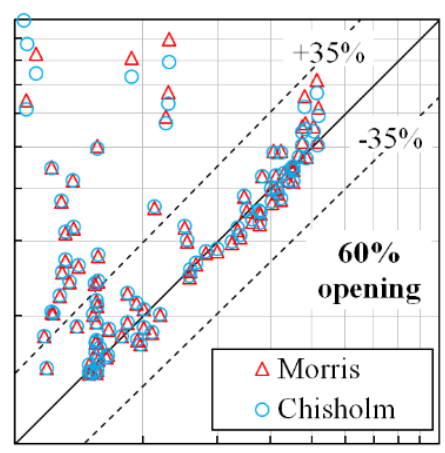

0.7

7.0
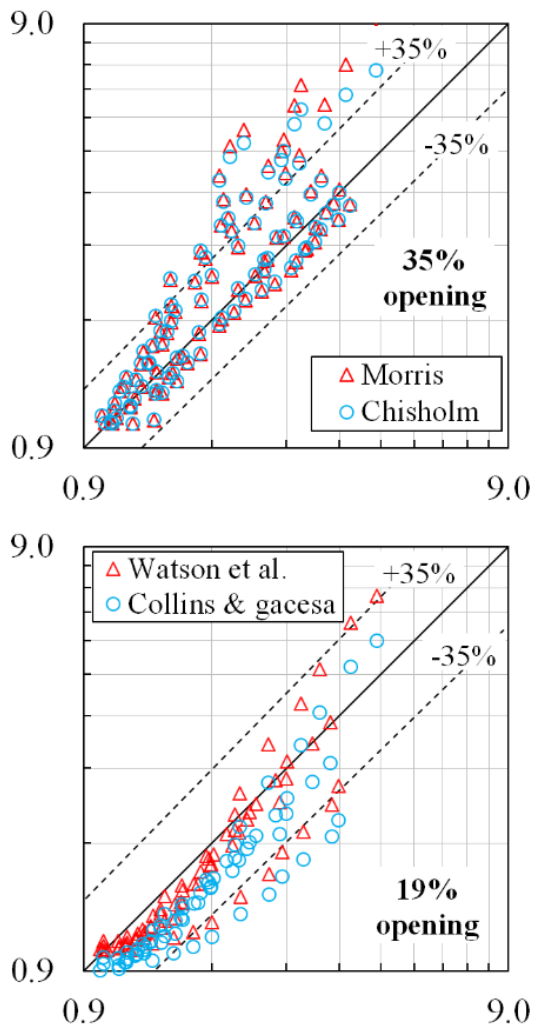

Experimental two-phase multiplier, $\Phi^{2}{ }_{L O}[-]$

Fig. 13. Comparison between predicted \& experimental two-phase flow multiplier 


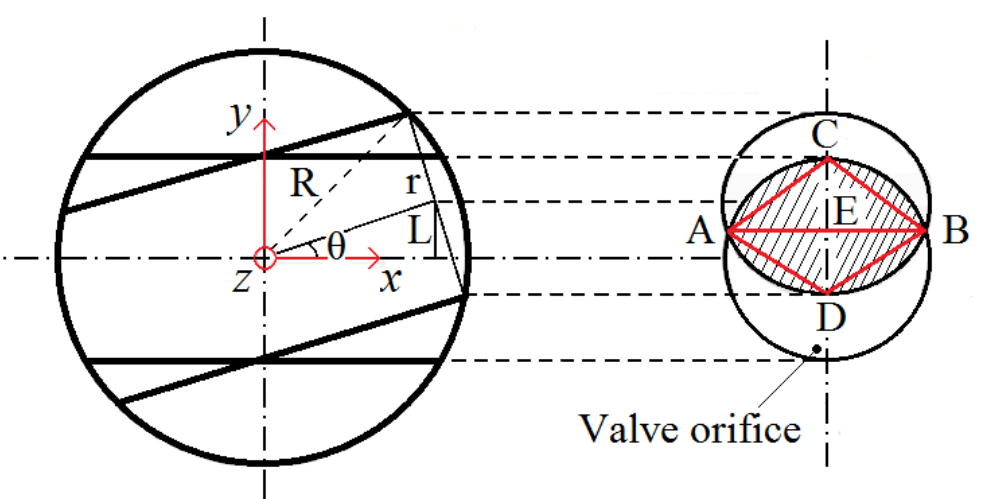

(a)

(b)

Fig. 14. Ball valve orifice area, (a) ball valve longitudinal-section,

(b) $x-y$ projection plane of the ball valve orifice area [10]. 


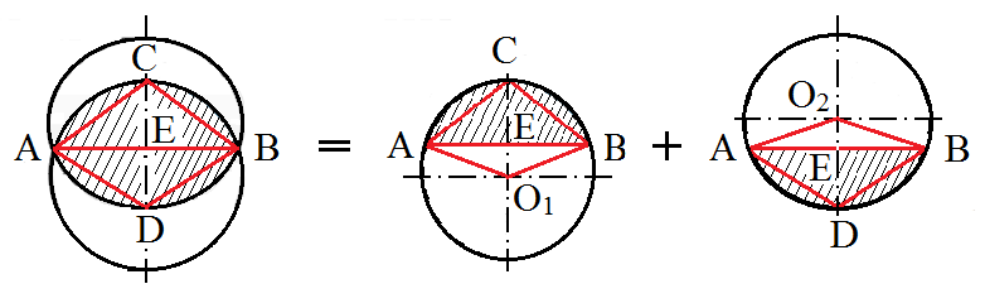

$\begin{aligned} & \text { Orifice area of the } \\ & \text { ball valve }\left(\mathrm{S}_{\text {flow }}\right)\end{aligned}=\begin{gathered}\text { Shaded area } 1 \\ \left(\mathrm{~S}_{\mathrm{ACB}}\right)\end{gathered}+\begin{gathered}\text { Shaded area } 2 \\ \left(\mathrm{~S}_{\mathrm{ADB}}\right)\end{gathered}$

Fig. 15. Details of the ball valve orifice area in $x-y$ projection plane [10]. 


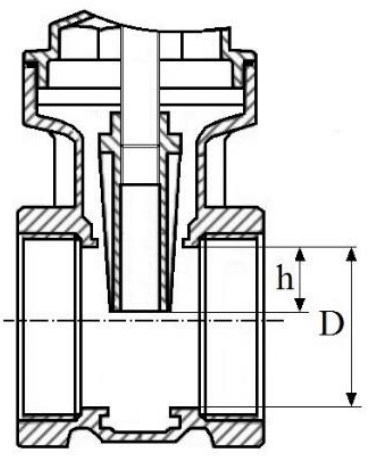

(a)

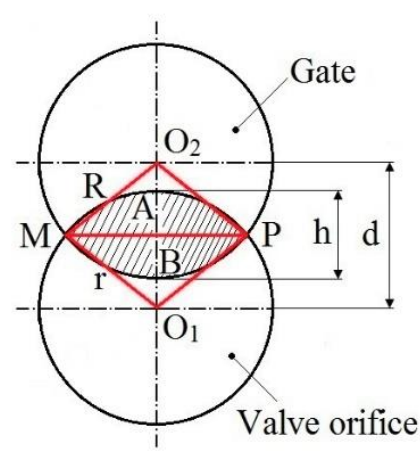

(b)

Fig. 16. Orifice area of gate valve: (a) Longitudinal-section of a gate valve and its coordinate system (b) Projection of orifice area on x-y plane. 
Table 1. Two-phase flow correlations of pressure drop multiplier in orifices and valves [19]

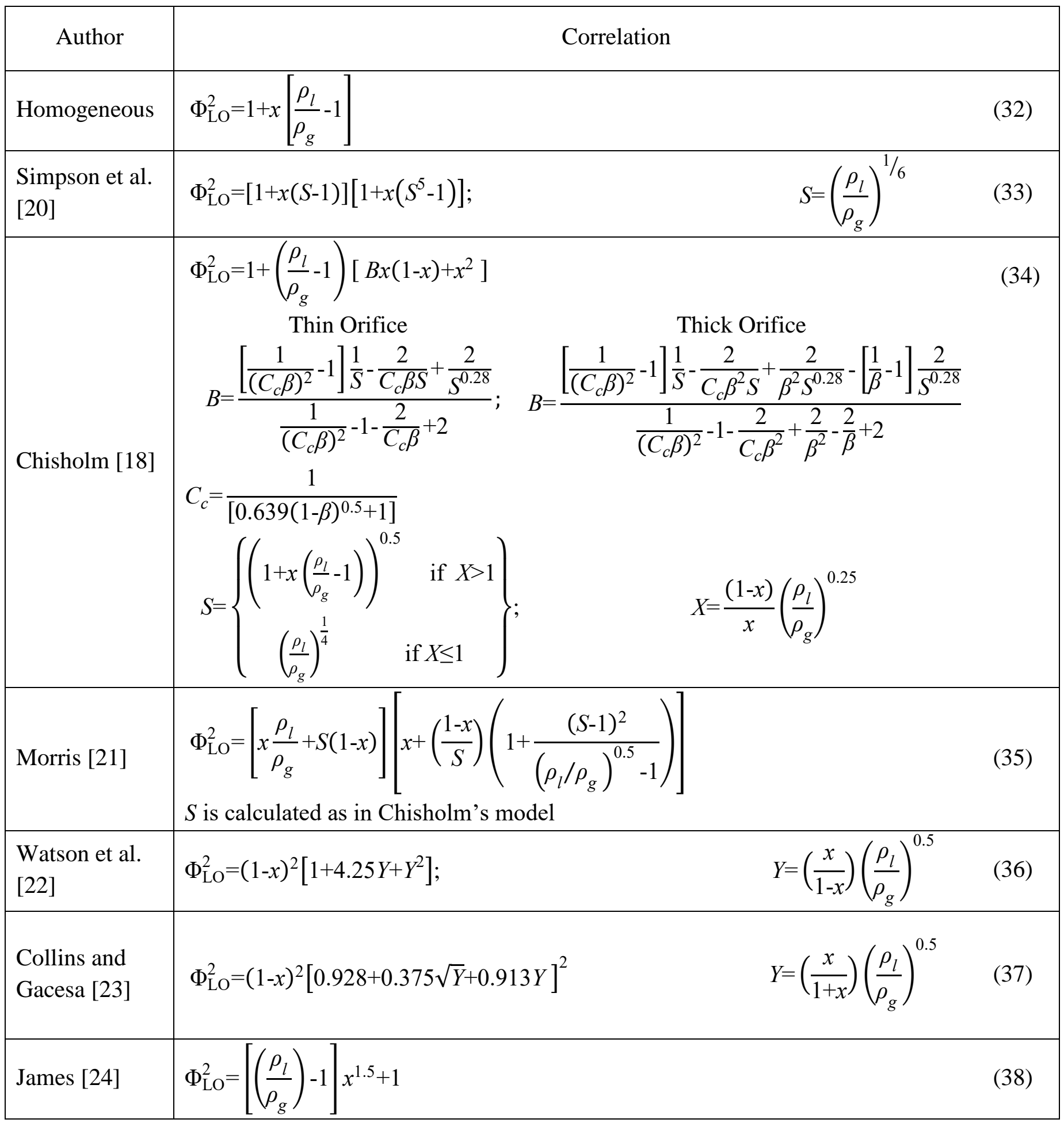


Table 2. Comparison of the experimental two-phase flow multiplier data and the selection of correlations

\begin{tabular}{lccccccccc}
\hline \multirow{2}{*}{ Model } & & \multicolumn{2}{c}{$80 \%$} & \multicolumn{2}{c}{$60 \%$} & $40 \%$ & $35 \%$ & $20 \%$ & $19 \%$ \\
\cline { 2 - 10 } & & G.V. & B.V. & G.V. & B.V. & G.V. & B.V. & G.V. & B.V. \\
\hline Morris [21] & $\mathbf{S}$ & 0.335 & 0.314 & 0.263 & 0.297 & 0.114 & 0.105 & 0.102 & 0.124 \\
\cline { 2 - 10 } & $\mathbf{F}$ & 0.834 & 0.752 & 0.857 & 0.845 & 0.897 & 0.907 & 0.883 & 0.848 \\
\hline Simpson et al. [20] & $\mathbf{S}$ & 0.300 & 0.298 & $0.248^{*}$ & 0.266 & $0.073^{*}$ & 0.089 & $0.092^{*}$ & 0.119 \\
\cline { 2 - 10 } & $\mathbf{F}$ & 0.831 & 0.793 & $0.880^{*}$ & 0.842 & $0.917^{*}$ & 0.901 & $0.917^{*}$ & 0.899 \\
\hline Chisholm [18] & $\mathbf{S}$ & $0.310^{*}$ & 0.290 & 0.239 & $0.272^{*}$ & 0.110 & $0.088^{*}$ & 0.087 & 0.103 \\
\cline { 2 - 10 } & $\mathbf{F}$ & $0.840^{*}$ & 0.757 & 0.863 & $0.851^{*}$ & 0.903 & $0.915^{*}$ & 0.892 & 0.857 \\
\hline Watson et al. [22] & $\mathbf{S}$ & 0.203 & 0.192 & 0.171 & 0.185 & 0.074 & 0.100 & 0.057 & $0.060^{*}$ \\
\cline { 2 - 10 } & $\mathbf{F}$ & 0.813 & 0.835 & 0.851 & 0.825 & 0.898 & 0.876 & 0.909 & $0.939^{*}$ \\
\hline James [24] & $\mathbf{S}$ & 0.213 & 0.192 & 0.184 & 0.203 & 0.101 & 0.131 & 0.082 & 0.075 \\
\cline { 2 - 9 } & $\mathbf{F}$ & 0.793 & 0.845 & 0.819 & 0.803 & 0.859 & 0.833 & 0.864 & 0.892 \\
\hline Collins and Gacesa [23] & $\mathbf{S}$ & 0.179 & $0.165^{*}$ & 0.150 & 0.167 & 0.089 & 0.107 & 0.058 & 0.059 \\
\cline { 2 - 9 } & $\mathbf{F}$ & 0.800 & $0.846^{*}$ & 0.829 & 0.811 & 0.862 & 0.840 & 0.869 & 0.905 \\
\hline
\end{tabular}

*Ideal: $\mathrm{F}=1$ and $\mathrm{S}=0$. 
Table 3. The geometric details of 11/4" (DN 32) ball valve.

\begin{tabular}{|c|c|c|c|}
\hline & Nominal diameter & $\mathrm{r}[\mathrm{mm}]$ & $\mathrm{R}[\mathrm{mm}]$ \\
\hline $1 \frac{1 / 4}{}$ & & 16 & 23.7 \\
\hline
\end{tabular}


Table 4. Results of 11/4" ball valve opening calibration.

\begin{tabular}{|c|c|c|c|c|}
\hline$\theta\left(^{\circ}\right)$ & $\theta(\mathrm{rad})$ & $S_{\text {Shaded }}\left[\mathrm{m}^{2}\right]$ & $\mathrm{S}_{\text {Flow }}\left[\mathrm{m}^{2}\right]$ & Openong [\%] \\
\hline 84.87 & 1.481 & $8.042 \mathrm{e}-4$ & 0 & $0 \%$ \\
\hline 65 & 1.134 & $6.537 \mathrm{e}-4$ & $1.505 \mathrm{e}-4$ & $19 \%$ \\
\hline 50 & 0.873 & $5.250 \mathrm{e}-4$ & $2.791 \mathrm{e}-4$ & $35 \%$ \\
\hline 40 & 0.698 & $4.269 \mathrm{e}-4$ & $3.773 \mathrm{e}-4$ & $47 \%$ \\
\hline 30 & 0.524 & $3.214 \mathrm{e}-4$ & $4.828 \mathrm{e}-4$ & $60 \%$ \\
\hline 20 & 0.349 & $2.118 \mathrm{e}-4$ & $5.924 \mathrm{e}-4$ & $74 \%$ \\
\hline 15 & 0.262 & $1.569 \mathrm{e}-4$ & $6.473 \mathrm{e}-4$ & $80 \%$ \\
\hline 0 & 0 & 0 & $8.042 \mathrm{e}-4$ & $100 \%$ \\
\hline
\end{tabular}


Table 5. The geometric details of 1/1/4" (DN 32) gate valve.

\begin{tabular}{|c|c|c|c|c|}
\hline & Nominal diameter & $\mathrm{r}[\mathrm{mm}]$ & $\mathrm{R}[\mathrm{mm}]$ & $\mathrm{D}[\mathrm{mm}]$ \\
\hline $1 \frac{1 / 4}{}$ & & & 15.35 & 26.3 \\
\hline
\end{tabular}


Table 6. Results of 11/4" gate valve opening calibration.

\begin{tabular}{|c|c|c|c|c|}
\hline Openong [\%] & $\mathrm{S}_{\text {Flow }}\left[\mathrm{m}^{2}\right]$ & $\mathrm{S}_{\text {Shaded }}\left[\mathrm{m}^{2}\right]$ & $\mathrm{d}[\mathrm{mm}]$ & $\mathrm{h}[\mathrm{mm}]$ \\
\hline 100 & $5.433 \mathrm{e}-4$ & 0 & 28.50 & 0 \\
\hline 80 & $4.346 \mathrm{e}-4$ & $1.087 \mathrm{e}-4$ & 20.49 & 8.01 \\
\hline 60 & $3.260 \mathrm{e}-4$ & $2.173 \mathrm{e}-4$ & 15.52 & 12.98 \\
\hline 40 & $2.173 \mathrm{e}-4$ & $3.260 \mathrm{e}-4$ & 11.14 & 17.36 \\
\hline 20 & $1.087 \mathrm{e}-4$ & $4.346 \mathrm{e}-4$ & 6.98 & 21.52 \\
\hline
\end{tabular}

